\title{
Federal Regulation and Aggregate Economic Growth
}

\author{
John W. Dawson \\ Department of Economics \\ Appalachian State University \\ Boone, NC, 28608-2051 \\ dawsonjw@appstate.edu \\ John J. Seater \\ Department of Economics \\ North Carolina State University \\ Raleigh, NC, 27695 \\ john_seater@ncsu.edu
}

\begin{abstract}
We introduce a new measure of the extent of federal regulation in the U.S. and use it to investigate the relationship between federal regulation and macroeconomic performance. We find that regulation has statistically and economically significant effects on aggregate output and the factors that produce it-total factor productivity (TFP), physical capital, and labor. Regulation has caused substantial reductions in the growth rates of both output and TFP and has had effects on the trends in capital and labor that vary over time in both sign and magnitude. Regulation also affects deviations about the trends in output and its factors of production, and the effects differ across dependent variables. Regulation changes the way output is produced by changing the mix of inputs. Changes in regulation and marginal tax rates offer a straightforward explanation for the productivity slowdown of the 1970s.

Keywords: Regulation; macroeconomic performance; economic growth; productivity slowdown.

JEL classification: E20; L50; O40

We thank Michele Boldrin, Tim Bollerslev, Michelle Connolly, Simeon Djankov, Ronald Gallant, Thomas Grennes, Bruce Hansen, Bang Jeon, Christopher Laincz, Oksana Leukhina, Aart Kraay, John Lapp, Marcelo Oviedo, Douglas Pearce, Denis Pelletier, Pietro Peretto, Martin Rama, and George Tauchen for helpful comments.
\end{abstract}




\section{Introduction}

Macroeconomists typically divide government economic activity into four broad classes: spending, taxation, deficits, and monetary policy. There is, however, a fifth class of activity that may well have important effects on economic activity but that nevertheless has received little attention in the macroeconomic literature: regulation. Although microeconomists have analyzed both the causes and effects of regulation for decades, macroeconomists have joined the discussion only much more recently, with a number of empirical studies suggesting that regulation has significant macroeconomic effects. Goff (1996) apparently was the pioneer, using factor analysis to construct a measure of total regulation in the United States and finding a type of Granger-causality effect of regulation on the path of output. Subsequently, development of several excellent sets of regulation data in cross-sections and panels of countries has led to many new studies of regulation's economic impact; see Nicoletti, Scarpetta, and O. Boylaud (2000), Nicoletti, Bassanini, Ernst, Jean, Santiago, and Swaim (2001), Bassanini and Ernst (2002), Djankov, LaPorta, Lopez-de-Silanes, and Shleifer (2002), Nicoletti and Scarpetta (2003), Djankov, McLiesh, and Ramalho (2005), and Loayza, Oviedo, and Serven (2004, 2005) for cross-section studies and Alesina, Ardagna, Nicoletti, and Schiantarelli (2003) and Kaufman, Kraay, and Mastruzzi (2003) for panel studies. These studies all conclude that regulation generally has deleterious effects on economic activity.

Existing measures of regulation have two important limitations, however, that restrict their usefulness in quantifying regulation's effects on the time path of the aggregate economy: (1) restriction to a small subset of regulations and (2) a short time dimension. For example, the OECD data set, used in several of the studies cited above, considers only product market and employment protection regulation (Nicoletti, Scarpetta, and Boylaud, 2000). The time span of the data ranges from none at all (the cross-section data sets) to a maximum of 20 years (the panel data sets of Nicoletti et al., 2001, and Kaufman et al., 2003). Restricting attention to a subset of regulations is problematic because, as we document below, the included regulations often are highly correlated both contemporaneously and intertemporally with the omitted regulations, leading to omitted variables bias in any regression analysis. A short time dimension makes analysis of dynamics difficult or impossible.

We construct a new measure of federal regulation in the US that overcomes these limitations, and we use our measure to analyze the macrodynamic effects of regulation. Our measure includes literally all federal regulations over a period of fifty-seven years. It is complementary to the existing measures, covering different 
dimensions of the body of regulation and useful for addressing different types of questions. Our measure is designed for time series analysis and thus is particularly well-suited to examining the impact of regulation on macroeconomic dynamics.

We use our series in an equation derived from endogenous growth theory to examine regulation's effect on the time paths of output and total factor productivity (TFP) and secondarily on the paths of labor and capital services. The major effect is on the growth rate of output. We find that regulation added since 1949 has reduced the aggregate growth rate on average by about one percentage point over our sample period. As usual with the compound effect of growth rates, the accumulated effect of a moderate change in the growth rate leads to large effects on the level over time. In particular, our estimates indicate that annual output by 2005 is about 56 percent of what it would have been had regulation remained at its 1949 level. Regulation also affects the dynamic adjustment paths of all variables, altering both the trend and level of each variable and usually having both contemporaneous and lagged effects. The effect of regulation on TFP is especially noteworthy. Increases in regulation, together with changes in marginal tax rates, explain much of the productivity slowdown of the 1970s. Regulation's effects differ for output, TFP, capital, and labor, implying that regulation alters the allocation of resources. Where our findings are comparable with those of previous cross-section and panel studies, they generally are consistent with them. In particular, our estimated growth rate reduction of about one percentage point falls in the middle of the range obtained from the cross-section and panel studies.

\section{Measuring Federal Regulation}

Any attempt to construct a measure of regulation will be limited by difficulties that arise from the nature of regulation itself. We explain those difficulties in the first part of this section. We then present our new measure and compare it to previous measures.

\subsection{Measurement Issues.}

When we study the effects of taxes on economic activity, we can appeal to economic theory to tell us which taxes to consider and how those taxes should enter our theoretical or empirical model. For example, theory tells us that one of the ways the income tax affects investment decisions is through the change in the rate of return to investment brought about by the marginal tax rate-that is, it is the marginal tax rate that matters and the channel is 
through the rate of return. Thus, theory tells us what to measure (the marginal tax rate rather than the average tax rate) and where to put it (in the rate of return). Similarly, when we study the effects of government expenditure on the path of gross domestic product, theory tells us to use the amount of purchases and to decompose it into transitory and permanent parts (Barro, 1981). Again, we are told what to measure (purchases rather than, say, total expenditure) and how to enter it into the model (decomposed into permanent and transitory parts). Unfortunately, regulation is more difficult to handle. How should one measure the amount of regulation contained in the prohibition “Thou shalt not pollute,” and how should it enter a macroeconomic model? As we shall see, modern growth theory actually does give us some guide into how to address the latter modeling issue, but it does not tell us exactly what to measure. There is no "marginal regulation rate" in either the theory or any available data. There also is no market in which regulations are traded, so there is no market price indicating their value. We thus unavoidably are limited to some kind of counting measure of the volume of regulation. A counting measure obviously is imperfect in that two identical values may comprise regulations of different types and, even within a given type, may have regulations of different stringency. However, if there are many kinds of regulation (as in fact there are in all countries included in regulation studies), it is reasonable to expect an index to provide a useful overall measure of regulation. In that regard, measures of regulation are no different from many other variables. Government purchases, physical capital, schooling, labor, and so on are composites whose effects may vary with the composition even though two reported values may be the same.

There is an indirect indicator that counting measures of regulation contain useful information, which is the results that arise from including them in regressions. If the measures contained no information, they should not be systematically related to dependent variables of interest. In fact, they routinely have coefficients that are both statistically significant and of the sign predicted by theory. For example, regulations that make it costly to start a business should be negatively associated with investment. That is exactly what has been found (Alesina, Ardagna, Nicoletti, and Schiantarelli, 2003).

The measures of regulation mentioned in the Introduction generally proceed by constructing indices based on binary indicators of whether or not various kinds of regulation exist, assigning a value of 1 to each type of regulation that exists and a 0 to those that do not exist. The index then is constructed as a weighted sum of all the binary indicators. Such measures capture the existence of given types of regulation but cannot capture their extent or 
complexity. Some measures therefore add indicators of the extent or effectiveness of regulation (see, for example, the detailed Annex in Nicoletti, Scarpetta, and Boylaud, 2000). The measure we propose is an alternative counting measure that is not binary and that captures at least some of the complexity of regulation. Specifically, our measure is the number of pages in the Code of Federal Regulations (hereafter, CFR). Although other researchers have proposed related measures, ours is more precise and covers a much longer time span. ${ }^{1}$ The CFR contains literally every federal regulation in existence during a given year, and it has a time span of more than 50 years. It thus is more comprehensive and covers a much longer time span than previous measures of regulation. Because all federal regulations must be published in the CFR, our page count measure must have at least a rough correlation with the "true" amount of regulation that should enter an economic model. If the CFR page count were zero, there would be no regulation, and it surely is reasonable to suppose that the more pages there are in the CFR, the more regulations there are. It also seems reasonable to suppose that the number of pages is positively related to the complexity of regulation because, at least on average, more complex regulations should require more pages to describe. In that case, our measure captures more than just the existence of a regulation.

We next provide a brief description of the Code of Federal Regulations, the measure of regulation we extract from it, and a brief comparison of our measure with predecessors. A more complete discussion appears in the Appendix.

\subsection{Brief History of the CFR}

The CFR contains all regulations issued by the federal government. It was first published in 1938 and was divided into 50 "titles," each pertaining to a major division of regulation, such as agriculture, banking, environment, labor, and shipping. The structure of 50 titles continues to this day. The second complete edition of the CFR was published in 1949. Annual supplements were published between 1938 and 1949, listing changes in regulations. Because of the way the annual supplements were done, it is difficult to use them to update the 1938 edition of the CFR to obtain annual page counts. After 1949, pocket supplements replaced the annual supplements, and updated versions of entire titles were published increasingly often. The pocket supplements were done differently than the annual supplements; together with the intermittent revised titles, they make it possible to construct annual page

\footnotetext{
${ }^{1}$ Friedman and Friedman (1979), Becker and Mulligan (1999), and Mulligan and Shleifer (2003).
} 
counts for the CFR between 1949 and 1969. ${ }^{2}$ Starting in 1969, the complete CFR has been published annually.

\subsection{Overview of the CFR Page Count Series}

Figures 1 and 2 show the time paths for the level and growth rate of the total page count of the CFR from 1949 to 2005, and Table 1 presents some basic statistics of the series. Over the sample period, the CFR page count increased by more than six-fold, from 19335 pages in 1949 to 134261 in 2005 . Regulation grows most of the time, but its growth rate varies a great deal. The growth rate has a mean of 0.035 and a standard deviation of 0.039 . Periods of negative growth are infrequent, and, when they do occur, the absolute value of the growth rate is small. By far, the fastest percentage growth occurred in the early 1950s. High growth also occurred in the 1970s, even though there was extensive deregulation in transportation, telecommunications, and energy. Deregulation in that period was more than offset by increased regulation in other areas, notably pertaining to the environment and occupational safety, as Hopkins (1991) has noted. The Reagan administration of the 1980s promoted deregulation as a national priority, and growth in the number of CFR pages slowed in the early and late 1980s. Nevertheless, total pages decreased in only one year, 1985. The 1990s witnessed the largest reduction in pages of regulation in the history of the CFR, with three consecutive years of decline. This reduction coincides with the Clinton administration's “reinventing government” initiative that sought reduced regulation in general and a reduction in the number of pages in the CFR in particular. (Interestingly, the greatest percentage reduction in the CFR did not occur during either the Reagan or Clinton administrations but rather in the first year of the Kennedy administration, 1961.) There thus are several major segments in regulation's time path, with corresponding breaks in trend (dates are approximate): (1) 1949 to 1960 (fast growth), (2) 1960 to 1972 (slow growth), (3) 1972 to 1981 (fast growth), (4) 1981 to 1985 (slow growth), (5) 1985 to 1993 (fast growth), and (6) 1993 to 2005 (slow growth). As we will see, these segments correspond to behavior of the aggregate variables of interest.

\subsection{Comparison with Other Measures of Regulation}

We present a brief comparison with earlier measures of regulation, restricting attention here to the two most important differences: the time span of the data and the comprehensiveness of the regulations included. A complete

${ }^{2}$ See the Appendix for details on the method of construction. Note in particular that we have accounted for changes in typeface and page sizes. 
discussion of all the differences between our measure and its predecessors is in the Appendix. ${ }^{3}$

Our measure spans 57 years. The earlier measures have short to non-existent time spans, the longest being 20 years and the shortest 1 year. The earlier measures cannot be used to study regulation's effects on dynamic adjustment paths, which requires following the evolution of variables through time. There is more hope of studying regulation's effects on average growth rates by using the cross-sectional dimension of the data to overcome the inadequate time dimension, but even there one must proceed with caution in light of Ventura's (1997) demonstration that the interpretation of cross-country growth regressions is confounded by the effects of international trade. Longrun growth and dynamic adjustment are intertemporal phenomena, best studied with time-series data. Our measure is naturally suited to studying them. The earlier measures, with their strong cross-section element but weak intertemporal element, are better suited for cross-sectional issues.

Our measure includes literally every regulation issued by the federal government, which makes it far more comprehensive than any of its predecessors. For example, the most widely used of the earlier data sets is the OECD cross-section measure described by Nicoletti et al. (2000) and extended in part to a 20-year panel by Nicoletti et al. (2001). The original OECD cross-section data are restricted to product market and employment protection regulation. Other types of regulation, such as environmental or occupational health and safety regulation, are ignored. The panel extension is restricted further to a small subset of seven non-manufacturing industries: gas, electricity, post, telecommunications, passenger air transport, railways and road freight. Furthermore, within this restricted set of industries, only a few types of regulations are included, varying by industry: barriers to entry (available for all industries), public ownership (all industries except road freight), vertical integration (only gas, electricity and railways), market structure (only gas, telecommunications and railways), and price controls (only road freight). Incomplete coverage leads to two problems: (1) omitted variables bias, and, in any time series study, (2) divergence between the time series behavior of subsets of regulation on the one hand and of total regulation on the other.

${ }^{3}$ The predecessors are Nicoletti G. , S. Scarpetta, and O. Boylaud (2000), Nicoletti, Bassanini, Ernst, Jean, Santiago, and Swaim (2001), Bassanini and Ernst (2002), Djankov, LaPorta, Lopez-de-Silanes, and Shleifer (2002), Nicoletti and Scarpetta (2003), Djankov, McLiesh, and Ramalho (2005), Loayza, Oviedo, and Serven (2004, 2005), Alesina, Ardagna, Nicoletti, and Schiantarelli (2003) and Kaufman, Kraay, and Mastruzzi (2003). 
Table 1 shows that the contemporaneous correlations of the various titles of the CFR are often quite high. ${ }^{4}$ Table 2 shows that the intertemporal cross-correlations also are quite high. Such high correlations imply that including just one type of regulation in a statistical analysis is likely to be misleading because of multicollinearity and omitted variables bias. As a particular example, consider Nicoletti et al.'s (2001) measure, which the authors interpret as "a proxy for the overall regulatory policies followed by OECD countries over the sample period” (p. 43). Their measure spans 1978-98 and shows a 66\% decline over that period. If we look at the page counts of CFR titles corresponding to the regulations included in Nicoletti et al.'s measure, we find that they behave similarly to Nicoletti et al's measure. For example, one of Nicoletti et al's regulation groups is air transport, railways, and road freight. In the CFR, those types of regulations are included in titles 23 (Highways), 46 (Shipping), and 49 (Transportation). The page count of titles 23, 46, and 49 behave qualitatively the same as Nicoletti et al.'s measure, dropping from a total of 8400 in 1978 to 8261 in 1998 . Nevertheless, the page count of the total CFR displays the opposite behavior, rising 47\% over 1978-98. The inescapable implication is that subsets of regulation are not reliable proxies for total regulation.

A final issue concerns the burden of regulation and the vigor of enforcement. Our measure controls for regulatory burden to some extent. The OECD data set measures regulatory burden by the presence or absence of a long list of regulatory requirements. It seems reasonable to suppose that the number of pages required to describe regulatory requirements varies directly with the number of requirements, on average at the very least. Our page count measure therefore should capture whatever regulatory burden is reflected in the number of regulatory requirements. In fact, our approach may give a more complete picture of regulatory burden than the OECD's measure because page counts indicate not only the presence or absence of particular provisions (a zero-one variable) but also their complexity (a continuous variable up to the inherent discreteness of numerical page counts), again on the reasonable assumption that more complex regulations require more pages of description. Another useful dimension of regulatory burden to measure would be the vigor with which regulations are enforced, but we were not able to find anything suitable. We considered using court cases or enforcement budgets, but we could find no useable data. Omitting vigor of enforcement is a problem only if enforcement vigor is correlated with the amount of

${ }^{4}$ Similarly, Loyaza et al. (2005) found very high correlations among their 7 indices of regulation. 
regulation itself, but we see in the historical record no reason to expect such a correlation. For example, the amount of regulation fell during the Kennedy, Reagan, and Clinton administrations, but none of those administrations was considered to be lax in the enforcement of the regulations that remained. Moreover, regulatory enforcement is conducted by quasi-independent regulatory commissions, at least partly insulated from political pressures. We therefore proceed on the assumption that variation in enforcement vigor is orthogonal to variation in the amount of regulation.

In summary, our page count measure has a much longer time span and much more comprehensive coverage than any other measure. It is well-suited to analyzing the effects of regulation on the dynamic behavior of the aggregate economy.

\section{Theory}

We divide theories of regulation into two categories: micro and macro, which we discuss separately.

\subsection{Microeconomic Theory of Regulation}

The microeconomic theory of regulation also divides into two types: those about the effects of regulation and those about its origins. A full discussion of either is far beyond the scope of the present paper and also unnecessary for our purposes, so we present only the briefest of summaries.

Even at the micro level, regulation's effects on economic activity often are not straightforward. For example, regulating the rate of return earned by public utilities seemingly should make the utility less profitable and so reduce its capital stock. However, in a well-known article, Averch and Johnson (1962) show that capital may rise. Even when regulation's effect on a firm is clear, the effect on the market often is not. Smokestack emission regulations may require a firm to invest in new capital, implying that capital should rise in response to the regulation, but some firms may close in the face of the new regulatory costs, reducing capital. The net effect on aggregate capital is ambiguous. Effects on production costs and thus output are even more difficult to predict. Effluent regulations increase the cost of business for the polluter and reduce his output but have the opposite effects on producers downstream. Again, the aggregate output effect is ambiguous. Moreover, types of regulation interact with each other and with the market structure of the regulated industry, typically leading to ambiguous effects. See Alesina et al. (2003) for a more extended discussion. Regulatory effects on labor also are complex; see Blanchard 
and Giavazzi (2003) for one treatment.

The origins of regulation are studied in a branch of the public choice literature. Djankov et al. (2002) present an excellent discussion of the literature, which we quickly summarize here. Pigou (1938) argues that regulation arises from government's attempt to improve social welfare by correcting market failures. Stigler (1971) proposes a much less benign theory of regulatory capture, in which the regulated firms gain control of the regulatory agency and use it to their advantage. McChesney (1987) offers the related idea that regulations are created for the benefit of politicians and regulators. Neither Pigou's nor Stigler's theories suggest any clear connection between aggregate variables and the amount of regulation. Even Pigou's completely benign view does not predict whether regulation will increase or decrease measured output. For example, regulation may lower measured output (many environmental regulations probably do so) or raise it (e.g., trust-busting). ${ }^{5}$ Neither Pigou's nor Stigler's theory suggests any reason to expect aggregate variables to cause changes in the amount of regulation. In contrast, McChesney's theory allows the possibility that politicians respond to the state of the aggregate economy by changing the amount of regulation. One might expect new regulations to appear in response to bad times, and indeed such behavior did occur in the 1930s with the Depression-era financial regulations. The Depression, however, was a unique event in American history, so one must be cautious in using Depression events as the basis of a general conclusion. In particular, it seems unlikely that a run-of-the-mill recession would spawn new regulation. Even the 2005 bailout of Fannie Mae and Freddie Mac seems to have been more an effort to save those two institutions than to respond to the aggregate economy's condition. Indeed, public attitudes have been becoming steadily more favorable toward increased regulation in general at least since 1995, according to opinion polls, with no apparent relation to the current state of the economy. ${ }^{6}$ Still, McChesney's theory does suggest a possible reason for aggregate variables to cause changes in the amount of regulation. We test that possibility below.

\subsection{Regulation and the Macroeconomy}

We are aware of no theory that addresses the effects that regulation has on the macroeconomy. Fortunately,

${ }^{5}$ Furthermore, growth theory suggests that anti-monopoly regulation, which would raise output in the short run by eliminating monopoly restrictions on supply, may reduce output in the long run by reducing the monopoly returns necessary to justify $R \& D$ and thereby reducing the rate of output growth.

${ }^{6}$ See the Wall Street Journal's front page article "Sour Economy Spurs Government to Grab a Bigger Oversight Role”, 25 July 2008. 
however, recent work by Peretto (2007a, 2007b, 2007c, 2008) analyzing the effects of taxes on economic growth can be readily adapted to our needs. We present a distilled and simplified version of Peretto's models, introduce the necessary modifications to add regulation, and use the result to motivate the equation that we use for estimation. We restrict attention to a bare bones description of the important components of Peretto's approach and omit all derivations. Readers interested in the details should consult Peretto's work.

The model is a second-generation endogenous growth model that eliminates the counterfactual scale effects of first-generation models by allowing entry of new firms. There is a government that collects taxes on wages, dividends, corporate profits, capital gains, and consumption, and spends the revenue on activities that do not enter any production or utility function. There is a final good sector, an intermediate goods sector, and a representative household. The sector for producing a final good $\mathrm{Y}$ is competitive with production function

$$
Y=\int_{0}^{M} \psi X_{i}^{\theta}\left(K_{i}^{\alpha} K^{1-\alpha} N_{i}\right)^{1-\theta} d i
$$

where $\psi$ is a constant (equal to total factor productivity), the $X_{i}$ are intermediate goods, $M$ is the mass (or range of varieties) of intermediate goods, $N_{i}$ is the labor employed in using $X_{i}, K_{i}$ the quality of intermediate $X_{i}$ (embodied in $\mathrm{X}_{\mathrm{i}}$ but augmenting the labor that uses it), and $\mathrm{K}$ is average quality $(1 / \mathrm{M}) \int \mathrm{K}_{\mathrm{j}} \mathrm{dj}$. The final good is the numeraire with price $\mathrm{P}_{\mathrm{Y}}=1$.

The intermediate goods sector is monopolistically competitive. Each intermediate goods firm transforms one unit of final good into one unit of intermediate good. It also invests $\mathrm{R}_{\mathrm{i}}$ units of final output in $\mathrm{R} \& \mathrm{D}$, which increases $\mathrm{K}_{\mathrm{i}}$ according to the $\mathrm{R} \& \mathrm{D}$ production function

$$
\dot{K}_{i}=R_{i}
$$

The intermediate goods firm faces a fixed operating cost $\phi \mathrm{K}_{\mathrm{i}}{ }^{\alpha} \mathrm{K}^{1-\alpha}$. The firm maximizes the present value $\mathrm{V}_{\mathrm{i}}$ of its dividend payments

$$
V_{i t}=\int_{0}^{\infty} D_{t} e^{-\frac{\bar{r}(t, s)}{1-t_{V} s}}=\int_{t}^{\infty} \frac{\left(1-t_{D}\right)\left(1-t_{\pi}\right)}{1-t_{V}}\left[X_{i s}\left(P_{i s}-1\right)-\phi K_{i s}^{\alpha} K^{1-\alpha}-R_{i s}\right] e^{-\frac{\bar{r}(t, s)}{1-t_{V}} s}
$$

where $\mathrm{D}$ is the dividend payment equal to the undiscounted part of the expression inside the second integral, $t_{D}, t_{\pi}$, and $t_{\mathrm{V}}$ are the tax rates on dividends, profits, and capital gains, $\mathrm{P}_{\mathrm{i}}$ is the price of the intermediate good, and $\bar{r}$ is the average interest rate in period s, [1/(s-t)] $\mathrm{r}(\mathrm{v}) \mathrm{dv}$. Households buy final goods for consumption, supply labor to earn 
wage income, and receive all dividend payments. New firms can enter the intermediate goods industry by paying a sunk cost $\beta X_{i t}$ proportional to the size of the new firm's operations $X_{i}$. Equilibrium requires that entry occur up to the point where the value of the incipient new firm equals the entry cost, that is, $V_{i}=\beta X_{i}$.

A representative household buys final goods for consumption, supplies labor to earn wage income, and receives all dividend payments. The number of household members grows at rate $\eta$. The household's size (i.e., the population) at any moment is $\mathrm{H}_{\mathrm{t}}=\mathrm{H}_{0} \mathrm{e}^{\mathrm{t}}$. For convenience, we impose the normalization $\mathrm{H}_{0}=1$. Each household member has the instantaneous utility function

$$
\ln u\left(C_{t} e^{-\eta t}, L_{t}\right)=\ln \left(C_{t} e^{-\eta t}\right)+\gamma \ln \left(1-L_{t}\right)
$$

where $\mathrm{C}$ is total household consumption, $\mathrm{L}$ is the fraction of time devoted to labor and $\gamma$ is positive. Total labor provided by the household is $\mathrm{N}_{\mathrm{t}}=\mathrm{L}_{\mathrm{t}} \mathrm{H}_{\mathrm{t}}=\mathrm{L}_{\mathrm{t}} \mathrm{e}^{\eta t}$. The household maximizes the intertemporal utility of all its members

$$
U_{t}=\int_{t}^{\infty} \ln u\left(C_{t} e^{-\eta t}, L_{t}\right) e^{-(\rho-\eta)(s-t)} d s
$$

where $\rho$ is the rate of time preference, subject to the flow budget constraint

$$
\frac{d(s M V)}{d t}=\left[\left(1-t_{D}\right) D+\left(1-t_{V}\right) \dot{V}\right] s M+\left(1-t_{L}\right) W N-\left(1+t_{C}\right) C
$$

where $t_{L}$ and $t_{C}$ are the tax rates on wage income and consumption and $\mathrm{W}$ is the real wage.

Finally, the government's budget constraint is

$$
G=t_{L} W N+t_{C} C+t_{\pi}(F-R) M+t_{D} D M+t_{V} \dot{V} M
$$

We thus have a model in which monopolistically competitive intermediate goods firms do R\&D to generate new knowledge that raises the quality of the intermediate goods. Higher quality intermediate goods are more productive in the final goods sector, so higher quality leads to a higher price for intermediate goods. New firms enter the intermediate goods sector whenever the present value of profits exceeds the sunk entry cost. Entry increases the variety of intermediate goods. Knowledge accumulation drives perpetual growth in income per person. In contrast, variety expansion has only level and transition effects, not permanent growth effects, because of fixed costs (Peretto and Connolly, 2007). Also, there is no scale effect because an increased population stimulates entry of new intermediate goods firms, which then must absorb resources to conduct R\&D on the new varieties of intermediate goods. 
For our purposes, the important result is the solution for final goods (= GDP). The general form is $\mathrm{Y}=$ $A(.) \mathrm{e}^{\mathrm{B}(.) t} \mathrm{C}($.$) , where \mathrm{A}($.$) is the intercept, \mathrm{e}^{\mathrm{B}(.)}$ is the trend, and $\mathrm{C}($.$) is a transient (or "cycle”). The arguments of the$ functions A, B, and C are subsets of the model parameters and tax rates, with each function's particular subset depending on the details of the model. A typical solution comes from Peretto (2007a) for the case where tax rates are exogenous and government expenditure responds to changes in revenue to satisfy the government budget constraint:

$$
Y_{t}=A\left(t_{L} ; \psi, \theta, \beta, \gamma, \rho, \eta ; K_{0}\right) e^{B\left(t_{\pi}, t_{D}, t_{V} ; \theta, \alpha, \beta, \phi, \rho, \eta\right) t} C\left(t_{L}, t_{\pi}, t_{D}, t_{V} ; \psi, \theta, \beta, \phi, \gamma, \rho, \eta\right)
$$

The various taxes have different effects on the path of Y: labor taxes affect the intercept but not the growth rate; corporate income, dividend, and capital gains taxes do just the opposite; all four of those taxes affect the transition path; and the consumption tax has no effects at all on the path of output. Similarly, the model parameters $\psi, \theta, \alpha, \beta$, $\phi, \gamma, \rho$, and $\eta$ enter the three functions in different ways. Peretto provides closed-form solutions for all three of the functions A, B, and T, with the specific forms depending on the details of the model. ${ }^{7}$ In all cases, the functions are irreducibly non-linear and mostly quite complicated. ${ }^{8}$ Peretto (2008) finds substantial quantitative effects of taxes on growth rates and social welfare.

Two important things that we learn from equation (1) are the overall form for output as a function of time and the way that taxes and model parameters affect output's time path. First, output is stationary about an exponential trend, not difference stationary. Changes in trend appear as breaks, not random shocks to a differencestationary process. The consensus among macroeconometricians for some time has been that the best model of the non-stationarity of aggregate data is precisely this kind of log-linear trend with breaks (Perron, 1989; Lumsdaine and

${ }^{7}$ One relevant detail is the nature of government purchases. Equation (1) is based on the assumption that the government sets the tax rates and adjusts purchases to satisfy the government budget constraint. If instead the government sets purchases and adjusts tax rates, a somewhat different form arises. As we discuss below, evidence on the behavior of government expenditures and tax rates suggests that equation (1) is the right form to use. form:

${ }^{8}$ For example, the intercept term $\mathrm{A}\left(\mathrm{t}_{\mathrm{L}}\right)$ in Peretto (2007a) is the simplest of the three functions and has the

$$
\frac{\left(1-t_{L}\right)(1-\theta)}{\left(1-t_{L}\right)(1-\theta)(1+\gamma)+\gamma(\rho-\eta) \beta \theta^{2}}
$$

which is neither linear nor log-linear in $t_{\mathrm{L}}$ or even $1-\mathrm{t}_{\mathrm{L}}$. The functions $\mathrm{B}($.$) and \mathrm{C}($.$) are far more complicated.$ 
Papell, 1997; Murray and Nelson, 2000). ${ }^{9}$ Thus equation (1) dovetails nicely with current econometric practice, although it differs slightly from the standard trend-break models in the econometrics literature in that it offers at least a partial explanation of trend breaks as consequences of government policy changes rather than as purely unexplained random phenomena. Second, equation (1) tells us which taxes enter each of the three terms on the right side of the equation. We will use these results in formulating our estimating equation.

In Peretto's models, taxes act by altering various net rates of return and so appear in the model as modifications of some of the underlying parameters. Regulation will enter the model in the same way, that is, by altering net rates of return and thus modifying underlying parameters. As with taxes, exactly how regulation enters the model depends on the specific regulation. For example, regulations that raise the cost of keeping employees, such as regulations on safety and retirement benefits, affect employment in a way qualitatively similar to Social Security taxes, which are a type of income tax. Other regulations can affect parameters in ways that taxes do not. There are seven fundamental parameters in equation (1): $\psi, \theta, \alpha, \beta, \phi, \gamma, \rho$, and $\eta$. Regulation may affect all of them. Various regulations certainly affect total factor productivity in the production of final goods $\psi$ (e.g., Title 7: Agriculture; Title 12: Banks and Banking; Title 15: Commerce and Foreign Trade; Title 30: Mineral Resources; Title 49: Transportation), the elasticity $\alpha$ of labor augmentation with respect to public knowledge (e.g., Title 37: Patents, Trademarks, and Copyrights), entry costs $\beta$ (e.g., Title 16: Commercial Practices), and fixed cost $\phi$ (e.g., Title 20: Employees’ Benefits; Title 29: Labor; Title 38: Pensions, Bonuses, and Veterans’ Benefits). Regulations may affect both the population growth rate $\eta$ and the rate of time preference $\rho$ by affecting the probability of dying (e.g., Title 21: Food and Drugs; Title 42: Public Health). ${ }^{10}$ Finally, regulation (e.g., Title 16: Commercial Practices) may even affect the leisure preference parameter $\gamma$ by affecting advertising, which in turn can alter tastes, as discussed by Sa (2007). We thus can expect regulation to enter the equation for output in each place that one of the underlying parameters enters. Ideally, we would enter different kinds of regulations in various parts of the equation, just as Peretto did with taxes, but data limitations make the ideal infeasible. The CFR organizes regulations by broad

${ }^{9}$ Fractional integration models have been shown to be observationally equivalent to trend-break models (Diebold and Inoue, 2001).

${ }^{10}$ The probability of dying affects the rate of time preference in the household choice model extended to include random time of death. See Blanchard (1985). 
categories called titles. Different regulations within the same title may do very different things. For example, some regulations in Title 29 (Labor) deal with job safety, and others deal with collective bargaining. We have page counts for each CFR title but not for lower levels. We thus cannot distinguish among regulations that may be very different and so are limited to including only our overall measure of regulation as follows:

$$
Y_{t}=A\left(R, t_{L} ; \psi, \theta, \beta, \gamma, \rho, \eta ; K_{0}\right) e^{B\left(R, t_{\pi}, t_{D}, t_{V} ; \theta, \alpha, \beta, \phi, \rho, \eta\right) t} C\left(R, t_{L}, t_{\pi}, t_{D}, t_{V} ; \psi, \theta, \beta, \phi, \gamma, \rho, \eta\right)
$$

where $R_{\mathrm{t}}$ is our measure of regulation. Regulation has three distinct types of effects: (I) level effects through the intercept term $\mathrm{A}($.$) , (ii) growth rate (or trend) effects through the exponent \mathrm{B}($.$) , and (iii) transition dynamic effects$ through the term $\mathrm{C}($.$) . We will estimate a version of equation (2) so that we can measure these three effects.$

\section{Estimation}

We begin our empirical investigation with a discussion of the variables to be examined and then turn to the econometric analysis.

\subsection{Variables To Be Examined}

We want to study the effect that federal regulation has on macroeconomic activity. As noted earlier, regulation grows most of the time, but there is great variation in the growth rate. That variation allows us to perform tests of the relation between regulation and the other variables. The obvious macroeconomic variable to examine is real aggregate output, and indeed that is the focus of our study. However, regulation presumably affects the economy in complex ways. It therefore seems worthwhile to examine how regulation affects not just output but also the determinants of output. If we suppose a Cobb-Douglas production function, then output $Y_{\mathrm{t}}$ is given by

$$
Y_{t}=D_{t} K_{t}^{\zeta} N_{t}^{1-\zeta}
$$

where $D_{\mathrm{t}}$ is total factor productivity (hereafter, TFP), $K_{\mathrm{t}}$ is capital services, and $N_{\mathrm{t}}$ is labor services. In what follows, we examine how regulation affects $D, K$, and $N$ as well as $\mathrm{Y}$.

\subsection{Data}

Regulatory activity $(R)$ is the total page count of the CFR, discussed above. Real output in the private business sector $(Y)$, private capital service flows $(K)$, and hours of labor services $(N)$ are from the Monthly Labor Review. Output $(Y)$ is real output in the private business sector, which is gross domestic product less output 
produced by the government, private households, and non-profit institutions. Capital $(K)$ is service flows of equipment, structures, inventories, and land, computed as a Tornqvist aggregate of capital stocks using rental prices as weights. Labor $(N)$ is hours worked by all persons in the private business sector, computed as a Tornqvist aggregate of hours of all persons using hourly compensation as weights. TFP is the Solow residual from a CobbDouglas production function assuming a capital share of thirty percent. We include two explanatory variables other than regulation: total government purchases $(G)$ and the federal marginal tax rate on personal income $(T)$. Government purchases is the sum of government consumption and government investment and is from NIPA. The marginal tax rate is from Stephenson (1998) and includes both the federal personal income tax and the Social Security tax. Although theory suggests different roles for different taxes, as shown in equation (2), data are not available for separate marginal tax rates on labor income, corporate profits, dividends, or capital gains. The main taxes on labor income are the personal income tax and the Social Security tax. Corporate profits are taxed twice, once by the corporate income tax and once by the personal income tax. The marginal corporate income tax is notoriously difficult to measure because almost-whimsical tax provisions that come and go over time, such as safe harbor leasing in the 1980s, have huge effects on the effective tax rate. Dividends are taxed at the personal income tax rate, but capital gains sometimes are taxed that way and sometimes are taxed under special provisions. All in all, Stephenson's measure of the effective marginal income tax rate seems a reasonable proxy for "the" tax rate. We thus replace the four separate tax rates $t_{L}, t_{\pi}, t_{D}$, and $t_{V}$ in equation (2) by Stephenson's single rate and modify the estimation equation accordingly, as discussed below. Figures 3 and 4 show the time series for $G$ and $T$. All data are annual observations for the U.S. over the period 1949-2005.

\subsection{Granger Causality Tests}

In the spirit of Hamilton’s (1983) pioneering study of oil and the macroeconomy, we begin with the completely non-structural method of Granger causality tests. Table 3 reports the results of bivariate Grangercausality tests between regulation and each of the macroeconomic variables for the period 1949-2005 using 4 lags. The tests are conducted on the first-differences of the logs in order to have stationary variables. Lower case variables denote the logs of the corresponding upper case variables. The notation $\Delta r+\Delta x$ refers to the test that $\Delta r$ does not Granger-cause $\Delta x$. The tests indicate unidirectional causality from $R$ to $Y$ and $T F P$, no causality in either direction between $R$ and $N$, and marginally significant causality from $K$ to $R$. The causality from $K$ to $R$ is 
insignificant at 3 or 5 lags, so we treat it as insignificant.

Hamilton (1983) concluded on the basis of similar Granger causality tests that oil prices played a major role in causing movements in US aggregate output. If we were to stop here, we would draw a similar conclusion about regulation. ${ }^{11}$ Rather than stop, however, we continue with an examination of reduced-form regressions to explore in more detail the relations suggested by our Granger causality tests. ${ }^{12}$

\subsection{Regression Models}

Our main empirical analysis is based on estimation of a version of equation (2). We begin with an explanation of how we use equation (2) to formulate a tractable estimating equation and then present our results. We then briefly discuss some alternative estimation approaches and the results we obtained.

4.4.A. The Regression Model. As remarked above, we use a trend-break model derived from endogenous growth theory for our estimation. We cannot use equation (2) directly for two reasons: (i) equation (2) assumes that the nature of each tax can be precisely specified (tax on labor income, tax on dividends, etc.), whereas our regulation data do not permit such precise specification for regulations (e.g., "environmental” regulations affect workplace safety, work practices, business practices, the cost of new capital, and so on), and (ii) equation (2) assumes taxes are proportional and observed, whereas we have good data on only the federal income tax, which is highly non-linear tax. Thus our measures of taxes and regulation will not enter the three functions $\mathrm{A}(),. \mathrm{B}($.$) , and \mathrm{C}($.$) in equation (2)$ in the same way as the separate tax rates. We therefore must approximate those functions.

We start with the following equation:

$$
X_{t}=\left(e^{\left[\beta+\sum_{j=0}^{J_{1}} \gamma_{j} Z_{t-J}+\sum_{j=0}^{J_{2}} \delta_{j} Z_{t-j}^{2}\right] t}\right)\left(e^{\alpha}\left[\prod_{j=0}^{J_{3}} Z_{t-j}^{\omega_{j}}\right] U_{t}\right)
$$

where: $X$ is any of our dependent macro variables $Y, T F P, K$, or $N$; $Z$ is an exogenous explanatory variable for $X$ (such as $R, T$, or $G$ ); $\alpha, \beta, \gamma_{\mathrm{j}}, \delta_{\mathrm{j}}$, and $\omega_{\mathrm{j}}$ are constants (note that we are reusing several Greek letters here with

${ }^{11}$ As did Goff (1996, Chapter 7). He estimated an ARMA model for each of several macro variables and then introduced a few lags of his factor-analysis measure of regulation, effectively performing a Granger-causality test. He found that regulation causes the dependent variables.

${ }^{12}$ We also performed Granger-causality tests on the individual titles of the CFR. Few individual titles Granger-cause any of the macroeconomic variables considered here, but the whole set of titles is jointly significant. With nearly 50 individual titles and only 57 observations, the tests have few degrees of freedom, leaving the results uninformative. This problem with degrees of freedom arises again later; we discuss it in more detail there. 
different meanings than they had earlier in the theory section); $J_{\mathrm{i}}$ are lag lengths; and $U$ is a log-normally distributed residual. Generalization to the case where $Z$ is a vector is straightforward.

The first term in parentheses in equation (3) is a trend term. The trend coefficient is a quadratic function of Z. The quadratic is simple and suffices for this first attempt at exploring the theoretically non-linear causal relation between regulation and trend breaks. It has some undesirable implications for extrapolation beyond the sample period, as we discuss below, so further research on functional forms for the trend coefficient would be useful. Note that (3) nests the simpler linearly detrended model with constant trend $\left(\gamma_{\mathrm{i}}=0, \delta_{\mathrm{j}}=0\right.$ for all $\left.I, j\right) .{ }^{13}$ The second large term in parentheses in (3) is a combination of the intercept and cycle terms $\mathrm{A}($.$) and \mathrm{C}($.$) in equation (2) that we$ explain in more detail presently.

Equation (3) is the form we use for estimation. It is not quite in the same form as equation (2), the growth equation that motivates it, because $Z$ may contain a trend of its own. Equation (2) collects all trend elements in the single term $\mathrm{B}($.$) . It is easy to see, however, that equations (2) and (3) are equivalent by decomposing Z$ into its trend and cycle components and then combining the trend component with the first term in parentheses in (3) to obtain a total trend term. We suppose $Z$ obeys

$$
Z_{t}=e^{\alpha_{Z}} e^{\beta_{Z} t} V_{t}
$$

where $\alpha_{Z}$ and $\beta_{Z}$ are constants, with $\beta_{z}$ being the trend in $Z$, and $V$ is a log-normally distributed residual that is the variation about the trend. Substituting into (3) and doing some straightforward algebra gives

$$
\begin{aligned}
X_{t} & =\left(e^{\left[\beta+\beta_{z} \sum_{j=0}^{J_{3}} \omega_{j}+\sum_{j=0}^{J_{1}} \gamma_{j} Z_{t-j}+\sum_{j=0}^{J_{2}} \delta_{j} Z_{t-j}^{2}\right] t}\right)\left(e^{\left(\alpha+\alpha_{z} \sum_{j=0}^{J_{3}} \omega_{j}-\beta_{z} \sum_{j=0}^{J_{3}} j \omega_{j}\right)}\left[\prod_{j=0}^{J_{3}} V_{t-j}^{\omega_{j}}\right] U_{t}\right) \\
& =A e^{B\left(Z_{t}\right) t}\left(\left[\prod_{j=0}^{J_{3}} V_{t-j}^{\omega_{j}}\right] U_{t}\right) \\
& =A e^{B t} C .
\end{aligned}
$$

where $A=\exp \left(\alpha+\alpha_{\mathrm{Z}} \Sigma \omega-\beta_{\mathrm{Z}} \Sigma \mathrm{j} \omega_{\mathrm{j}}\right)$ and $C=\left(\Pi \mathrm{V}_{\mathrm{t}-\mathrm{j} .}{ }^{\omega}\right) \mathrm{U}_{\mathrm{t}}$. Equation (4) has the same form as equation (2).

The first term $A$ in (4) is a constant. The second term is the trend with trend coefficient $B\left(Z_{t}\right)=\beta+\beta_{z} \Sigma \omega_{j}$ $+\Sigma \gamma_{\mathrm{j}} Z_{\mathrm{t}-\mathrm{J}}+\Sigma \delta_{\mathrm{j}} Z_{\mathrm{t}-\mathrm{j}}^{2}$. The first term inside $\mathrm{B}\left(Z_{\mathrm{t}}\right)$ is the constant $\beta$, which captures trend elements apart from any

\footnotetext{
${ }^{13}$ That is, a model of the form $x_{t}=\alpha+\beta t+\sum \omega_{i} z_{t-i}+u_{t}$.
} 
effects of $Z$. In particular, it would be the trend in $X$ if $Z$ were held constant, a fact we use in the analysis below. The last three terms in $\mathrm{B}\left(Z_{\mathrm{t}}\right)$ collect the various effects of $Z$ on the trend in $X$. In what follows, we refer to the first term $\beta$ as the trend-apart effect (because it captures the trend that would be present if all the exogenous variables were trendless), the second term $\beta_{\mathrm{z}} \Sigma \omega_{\mathrm{j}}$ as the trend-intercept effect of $Z$, the third term as the trend-linear effect, and the fourth term as the trend-quadratic effect. The trend-intercept effect is constant. Below, we discuss counterfactual paths that would have emerged if exogenous variables had been held constant. Doing that requires distinguishing among the quantities $\beta, \omega \beta_{z}$, and $\beta+\omega \beta_{z}$. The third term in (4) consists of the compound residual, $U\left(\Pi V^{\omega}\right)$ and is the cycle term. It corresponds to $\mathrm{C}($.$) in equation (2). Because X$ is trend-stationary, the compound residual is purely transient, causing fluctuations about trend. The term $\Pi V^{\omega}$ captures the part of the residual due to Z's deviation from its trend. We call this transient component the cycle effect. ${ }^{14}$ When $\mathrm{Z}$ equals its "normal” (or balanced growth) value, there is no transient effect, $\mathrm{V}_{\mathrm{t}-\mathrm{j}}=1$ for all $j$, and the only remaining level effect arises from the intercept term $e^{\alpha_{Z}}$.

Transition dynamics appear in two places in equation (4): the lagged values of the explanatory variables included in the growth rate and the lagged values included in the cycle effect. The balanced growth rate is the value of the growth rate in (4) when $Z$ is constant. When $Z$ changes, the balanced growth rate also changes, causing transition dynamics in going from the old balanced growth path to the new one. Changes in $Z$ induce additional transition dynamics through the cycle effect. The cycle effect captures movements about a given growth path. The same type of distinction appears in discrete-time ARIMA models in which a variable's level has a growth term and a random term, and the growth term itself is stochastic with a random term, such as

$$
\begin{gathered}
X_{t}=W_{t}+\phi(L) u_{t} \\
W_{t}=W_{t-1}+\theta(L) v_{t}
\end{gathered}
$$

Both $\mathrm{u}_{\mathrm{t}}$ and $\mathrm{v}_{\mathrm{t}}$ cause transition dynamics. The growth term that appears in the transition dynamics here was absent from equation (2). It arises from time variation in the regulation and tax parameters which were treated as constant in equation (2). Peretto (2007a) restricted his analysis to an economy that starts off the balanced growth path (and

${ }^{14}$ The $U$ component of the compound residual can include any exogenous variable not subject to analysis. The trends in such variables are included in the trend-apart term $\beta$, so that $U$ captures the transient components. 
therefore has transition dynamics) but that has constant values for all policy parameters. In contrast, we must allow changes in the policy parameters to capture the variation in regulation and taxes over our sample period, so we also must include the growth term in the transition dynamics.

4.4.B. Explanatory Variables and Exogeneity. We examine the sensitivity of our endogenous macro variables to three policy variables $R, G$, and $T$; that is, the variable $Z$ in (1) is the vector $(R, G, T)$ and the parameters $\gamma, \delta$, and $\omega$ are also vectors. We have not pursued the possibility of decomposing $G$ into major parts (such as federal versus state and local, or national defense versus road building), even though different kinds of expenditure almost certainly have different effects on the economy and may interact with regulation in different ways. Similarly, we ignore government debt, which is the correct procedure under the assumption of Ricardian equivalence. Most of the empirical investigations of regulation cited earlier ignore $G$ and $T$. We find that inclusion of $T$ has large quantitative (but not qualitative) effects on the estimates of regulation's macroeconomic impact. ${ }^{15}$

Before we can proceed to estimation, we must determine whether the explanatory variables are econometrically exogenous. The Granger-causality tests for $R$, discussed above, show no causality running from any of the dependent variables to $R$, implying exogeneity of $R$. We performed additional Granger-causality tests (not reported) of the exogeneity of $G$ and $T$. The tests stabilize at about 4 lags and indicate statistical exogeneity of $T$ at the $5 \%$ level. In contrast, $G$ frequently appears to be endogenous, with causality never running from $G$ to the macro variables of interest but frequently running from them to $G$. These results are consistent with government setting tax rates and then choosing $G$ to satisfy the government budget constraint. In light of these results, we treat $R$ and $T$ as exogenous. Exploration of regressions that included $G$ showed no important differences from regressions that omitted it, so henceforth we ignore $G{ }^{16}$

4.4.C. Estimation Results. When we replace $Z$ by the vector $(R, T)$ in equation (3), we obtain the following equation for the evolution of X:

\footnotetext{
${ }^{15}$ In this regard, our results differ from those in Alesina et al. (2003), whose estimates of regulatory impact are insensitive to inclusion or omission of fiscal policy variables.

${ }^{16}$ The irrelevance of $G$ in the regressions is not surprising in light of the shape of $G$ 's time path, shown in Figure 3. The path is essentially a trend with little variation about the trend.
} 


$$
X_{t}=\left(e^{\left[\beta+\sum_{j=0}^{J_{1}^{R}} \gamma_{j}^{R} R_{t-J}+\sum_{j=0}^{J_{2}^{R}} \delta_{j}^{R} R_{t-j}^{2}+\sum_{j=0}^{J_{1}^{T}} \gamma_{j}^{T} T_{t-J}+\sum_{j=0}^{J_{2}^{T}} \delta_{j}^{T} T_{t-j]}^{2}\right] t}\right)\left(e^{\alpha}\left[\prod_{j=0}^{J_{3}^{R}} R_{t-j}^{\omega_{j}^{R}}\right]\left[\prod_{j=0}^{J_{3}^{T}} T_{t-j}^{\omega_{j}^{T}}\right] U_{t}\right)
$$

The estimating equation is obtained by taking the natural log of (5):

$$
x_{t}=\alpha+\left[\beta+\sum_{j=)}^{J_{1}^{R}} \gamma_{j}^{R} R_{t-j}+\sum_{j=0}^{J_{2}^{R}} \delta_{j}^{R} R_{t-j}^{2}+\sum_{j=0}^{J_{1}^{T}} \gamma_{j}^{T} T_{t-j}+\sum_{j=0}^{J_{1}^{T}} \delta_{j}^{T} T_{t-j}^{2}\right] t+\sum_{j=0}^{J_{3}^{R}} \omega_{j}^{R} r_{t-j}+\sum_{j=0}^{J_{3}^{T}} \omega_{j}^{T} \tau_{t-j}+u_{t}
$$

Note that equation (6) derives from a coherent theory of endogenous growth. It contains no lagged dependent variables because the underlying theory does not predict the presence of such variables, as shown in equation (2). It also is not a VAR. VARs usually can be considered as linear approximations to a poorly understood theoretical model, useful when the theory provides little guidance on the correct specification. In contrast, we have a welldeveloped theory providing a closed-form solution. We must approximate that solution because of the data limitations discussed above, but our approximations preserve the basic structure emerging from the theory, which does not include a lagged dependent variable.

In estimating (6), we chose the lag lengths $J_{\mathrm{x}}$ by imposing an initial value of 3 on all the $J_{x}$ and searching, subject to two restrictions, over all possible smaller values to find that which minimized the Schwarz-Bayes Criterion (SBC). The restrictions on the search procedure were (1) the constant always was retained and (2) no variable could be omitted unless all of its more-lagged values also were omitted. For example, even if the lowest SBC value was obtained with a model that excluded $\mathrm{Z}_{\mathrm{t}}$ but retained $\mathrm{Z}_{\mathrm{t}-1}$, that model was not considered. Exclusion of $Z_{t}$ would be allowed only if $Z_{t-1}$ also was excluded. The reason for imposing this restriction was that, with annual data, it did not seem reasonable to suppose that a variable could have an effect only with a one-period lag. The residuals were serially correlated, so we used a Newey-West correction. ${ }^{17}$ Table 4 reports the estimation results for the four macro variables of interest. Part I of the table reports estimated values for all coefficients pertaining to regulation, and Part II reports all other parameter estimates. Very few lagged variables are significant, so to save

${ }^{17}$ We tried two other estimation methods. Instead of using a Newey-West correction, we estimated subject to the following ARMA model for $\mathrm{u}_{\mathrm{t}}$ :

$$
u_{t}=\sum_{j=1}^{J} \phi_{j} u_{t-j}+e_{t}+\sum_{m=1}^{M} \theta_{m} e_{t-m}
$$

where $e$ is white noise. The results were essentially the same as those with the Newey-West correction. We also tried choosing lag lengths by dropping lag terms until we arrived at one that was individually significant. Again, the main conclusions were unchanged. 
space Table 4 is restricted to those lags that had significant coefficients in at least one equation.

Regulation has significant effects on all four dependent macro variables, entering with both trend and cycle terms. In some cases regulation enters with lags, indicating dynamic responses in the dependent variables. Also, the coefficient patterns and magnitudes differ across dependent variables, indicating compositional effects. As we have seen above, regulation can have two kinds of effects on a dependent variable's trend: a shift in the trend (the trendintercept effect) and breaks in trend (the trend-linear and trend-quadratic effects). Our results indicate that both kinds of effects are present. The trend-intercept effect is the product of regulation's trend $\beta_{\mathrm{R}}$ and the sum of the $\omega_{j}^{\mathrm{R}}$ coefficients. The latter are reported in Table 4, and the former is obtained by estimating the equation $r_{t}=\alpha_{R}+\beta_{R} t+$ $v_{\mathrm{t}}$. The estimated value of $\beta_{\mathrm{R}}$ is 0.0322 . Estimating the analogous equation for the tax rate gives a trend in $T$ of 0.0058 .

4.4.C.1: Output. For output, there is only one $\omega_{j}{ }^{R}$ coefficient, whose value is -0.406 . Its product with $\beta_{R}$ is -0.013 , indicating that regulation shifts the trend in output down by one and a third percentage points. That shift, being a reduction in the intercept of the trend coefficient function $\mathrm{B}\left(R_{\mathrm{t}}\right)$, is uniform over time. In addition, regulation has time-varying effects on output's trend through the trend-linear and trend-quadratic terms of the coefficient function $\mathrm{B}\left(R_{\mathrm{t}}\right)$. The sum of trend-linear coefficients is positive, causing output's trend to rise on net as regulation grows, and the trend-quadratic coefficient is negative, indicating that the trend-quadratic effect is negative and causes output's trend to fall as regulation grows. We thus have a non-linear effect of regulation on output's trend. Figure 5 shows the total effects of regulation on output's trend over time. The effect is always negative but is nonlinear. Growth in regulation raised output's trend (that is, made it less negative) until about 1980 and then reduced it. The average value of the negative effect is 0.008 , or eight-tenths of a percentage point.

The large negative value of $\omega_{0}$ indicates that regulation also has a substantial cycle effect on output. We can determine the total effect of the trend and cycle terms by using the parameter estimates and regulation data to calculate a counterfactual value of output that would have obtained had regulation stayed at its 1949 level. ${ }^{18}$ Figure $^{\circ}$

\footnotetext{
${ }^{18}$ For example, in the trend term we replace $\mathrm{R}_{\mathrm{t}}$ with $\left(\mathrm{R}_{\mathrm{t}}-\mathrm{R}_{1949}\right)+\mathrm{R}_{1949} \equiv \Delta \mathrm{R}_{\mathrm{t}}+\mathrm{R}_{\mathrm{t}}$ and replace $\mathrm{R}_{\mathrm{t}}^{2}$ with $\left[\left(\mathrm{R}_{\mathrm{t}}\right.\right.$ $\left.\left.\mathrm{R}_{1949}\right)+\mathrm{R}_{1949}\right]=\left(\Delta \mathrm{R}_{\mathrm{t}}\right)^{2}+2 \mathrm{R}_{\mathrm{t}} \Delta \mathrm{R}_{\mathrm{t}}+\left(\mathrm{R}_{\mathrm{t}}\right)^{2}$, multiply by the appropriate estimated trend coefficients $(\gamma$ and $\delta)$, and collect all terms containing $\Delta \mathrm{R}_{\mathrm{t}}$. Similarly, in the cycle term we replace $\mathrm{R}_{\mathrm{t}}$ with $\mathrm{R}_{1949}\left(\mathrm{R}_{\mathrm{t}} / \mathrm{R}_{1949}\right)$, raise to appropriate estimated power $(\omega)$, and collect all terms involving ratios of the form $\left(\mathrm{R}_{\mathrm{t}} / \mathrm{R}_{1949}\right)^{\omega}$. Finally, dividing actual output by the trend arising from the terms containing $\Delta \mathrm{R}_{\mathrm{t}}$ and by the cycle components $\left(\mathrm{R}_{\mathrm{t}} / \mathrm{R}_{1949}\right)^{\omega}$ is equivalent to setting $\Delta \mathrm{R}$ to zero and $\left(\mathrm{R}_{\mathrm{t}} / \mathrm{R}_{1949}\right)^{\omega}$ to one, thus giving a counterfactual value of output under the restriction that regulation remained
} 
6 plots the ratio of actual $Y$ to counterfactual $Y$. The ratio falls over the sample period, indicating that actual output fell relative to what it would have been had regulation not grown. The pattern is irregular. The ratio first falls until about 1960, then is nearly constant for about 15 years, then falls again for about 20 years, rises sharply for five years until 2000, and then falls sharply to 2005. The overall decline in output relative to its counterfactual is large. By then end of the sample period, output is down to 56 percent of its counterfactual. This large effect arises mostly from compounding the reduction in output's trend growth rate caused by regulation and also from the accumulated cycle effects. Using the formula $0.56=\mathrm{e}^{\beta * 57}$, where $\beta^{*}$ is the realized average reduction in output's growth rate and 57 is the number of years in the sample, we can calculate that $\beta^{*} \approx-0.010$, or about one percentage point. As noted above, the average reduction in output's trend is about 0.008 . The discrepancy of 0.002 reflects the fact that the regulation-induced reduction in output's trend is not constant but rather varies over time, as shown in Figure 5, and it interacts with the time-varying cyclical effects.

An estimated reduction in the annual growth rate of 1.0 or even 0.8 percentage point is large. It is, however, consistent with the results from the cross-section studies of the effects of regulation on growth. Loayza, Oviedo, and Sevren find that countries with above-average amounts of regulation could raise their growth rates by 0.4 to 1.3 percentage points (2004) or 0.3 to 1.7 percentage points (2005) if they would reduce their regulation to the median cross-country level. Our estimates of regulation's effect on output's trend are shown in Figure 5 and vary from -0.46 to -1.09 percentage points, well within the range reported by Loayza, Oviedo, and Sevren. Such agreement is remarkable given the very different construction methods and coverage of the data sets.

A large effect of regulation on economic growth also is consistent with the calibration results of Parente and Prescott (1999). They analyze general "barriers to riches,” but regulations constitute a large element of such barriers. Indeed, their Chapters 6 and 7 are almost exclusively about barriers imposed by regulations. Their calibration results find that such barriers explain most of the large cross-country differences in both levels and growth rates of income per person.

4.4.C.2. Opportunity Cost of Regulation. Attempts in the literature to measure the cost of regulation have been confined to compliance cost. The estimates are large. For example, Crain and Hopkins (2001) estimate the cost of

at its 1949 level. 
all federal regulation (not just post-1949 regulation) to be about 8 percent of current GDP, or about $\$ 1.1$ trillion in 2007. ${ }^{19}$ Our results suggest another element of cost that has not been considered previously: the opportunity cost arising from reduced GDP. The magnitude is many times larger than the compliance cost. The ratio of actual to counterfactual output was 0.56 in 2005 . If we assume that the same ratio applies today, we can calculate immediately the opportunity cost of regulation added since 1949. In 2007, nominal GDP was \$14 trillion. Had regulation remained at its 1949 level, current GDP would have been about \$25 trillion, an increase of \$11 trillion. With about 140 million households and 300 million people, an annual loss of $\$ 11$ trillion converts to $\$ 78,600$ per household and \$36,700 per person. Another way to put it, perhaps a little too dramatically, is that each page of federal regulation added since 1949 today costs the economy roughly \$82.1 million in foregone output per year. Furthermore, our estimates indicate that the opportunity cost will grow at a rate of about 1 percent a year (the average amount by which output's overall growth rate was reduced over the sample period), if regulation is merely kept at its 2005 level and not increased further. ${ }^{20}$

Three other aspects of the output opportunity cost are noteworthy. First, our figures are net costs. They are based on the change in total product caused by regulation and so include positive as well as negative effects. Our results thus indicate that whatever positive effects regulation may have on measured output are outweighed by the negative effects. Second, our measure does not include any non-production benefits of regulation. The nonproduction benefits could be both large and growing. Pollution, for example, presumably grows as unregulated industrialization expands. The cost of pollution may grow non-linearly. Those costs have been reduced by environmental regulation, and if regulation has reduced the growth rate of pollution, then it correspondingly has introduced a growing benefit that is not included in measured output. We do not attempt to measure such benefits

${ }^{19}$ This 8 percent excludes the cost of tax compliance, which Crain and Hopkins included. We exclude tax compliance cost because taxes generally are not considered regulations. Tax compliance cost amounts to about one half of one percent of GDP.

${ }^{20}$ Of course, because we have restricted our functional form to a quadratic, ridiculous results can be obtained by extrapolating far beyond the sample period. If regulation continues to grow, the negative terms take over and eventually output growth becomes negative, driving output toward zero as time passes. Such behavior obviously would not be tolerated by society, and the process governing the evolution of regulation would change. The problem is exactly the same as using a quadratic utility function to approximate the true function: it can work quite well locally but will give nonsensical results if abused. These problems of extrapolation are not relevant to our discussion here, which is confined to behavior within the sample period. 
here, confining our analysis strictly to measured output. Consequently, we emphasize that our results offer no conclusion on whether regulation is a net social benefit. ${ }^{21}$ They do, however, make clear that the cost of regulation is substantial and must be taken seriously in any evaluation of regulation's net social benefit. Third, our estimated opportunity cost pertains only to regulation added since 1949. We have no way to measure the opportunity cost associated with regulation up to 1949. It seems certain that some regulation has a negative opportunity cost, that is, a net positive effect on GDP. Surely GDP would be lower in the absence of traffic regulations or organized patent procedures. However, most of those most basic regulations were in place well before 1949, so for our work their benefits are simply a given impounded in the intercept.

4.4.C.3: TFP and the Productivity Slowdown. Figures 7 and 8 plot the growth rates of output and TFP. It is clear from the Hodrick-Prescott filtered series that the two variables move closely together with closely matched turning points. It therefore seems especially worthwhile to examine in some detail the effects that regulation has on TFP. Comparing Figure 8 with Figures 1, 2, and 4 suggests that regulation and taxes had something to do with TFP's behavior. TFP growth drops abruptly at the start of the sample, but that seems to be an artifact of the leverage that the first point in the sample has on the initial part of the Hodrick-Prescott filtered series. If we ignore that episode, then TFP really starts falling sometime in the mid 1960s, stops falling in the early 1980s, and grows slowly after that. The falling growth rate between about 1965 and 1980 is the well-known "productivity slowdown.” The marginal tax rate and the growth rate of regulation began rising at almost exactly the same time as TFP's growth rate turned down in the mid 1960s. Regulation's growth peaked in the second half of the 1970s, a little before TFP turned back up, and even became negative in the mid-1990s (see Figure 2). Tax rates peaked at almost exactly the same time that TFP bottomed out, stopping their rise around 1980 and falling somewhat afterward. Clearly, major changes in TFP correspond to major changes in R and T.

We can use our parameter estimates to quantify this impressionistic visual analysis. The second column of Table 4 reports the TFP estimates. Using those in the same way as we did for output, we can calculate the effects of regulation and taxes on TFP. Figure 9 shows the effect of regulation on TFP's trend. The effect is negative throughout the sample period, but there is sharp increase in the steepness of the slope in the early 1970s,

\footnotetext{
${ }^{21}$ Indeed, Peretto (2008) finds that changes in tax rates can reduce the growth rate of output but raise social welfare. The same divergence could happen with regulation.
} 
corresponding to the large increase in environmental and occupational, health, and safety regulation. Figure 10 shows the change in the ratio of actual TFP to counterfactual TFP obtained by holding regulation at its 1949 level. As with output, there is an initial point artifact. Ignoring that, we see that the change in the ratio is about zero in 1965 and then becomes increasingly negative until about 1980. After that, the change rises gradually until about 1998, after which it falls again. Throughout the period after 1965, the change is negative, indicating a persistent (though far from constant) negative effect of regulation on TFP.

Taxes also play a role in explaining TFP growth. Figure 11 plots the change in the ratio of actual TFP to counterfactual TFP obtained by holding the marginal tax rate at its 1949 level. Ignoring the usual initial point artifact, we see that the graph turns downward in about 1965, which is about the start of the productivity slowdown. The graph turns slightly upward around 1975 and then sharply upward around 1996.

Changes in regulation and taxes reinforce each other in their effects on the path of TFP in the mid-1960s and late 1970s. They oppose each other after about 1998, leading to a flat path for TFP after that date. Figure 12 shows the combined effects of regulation and taxes on TFP, plotting the change in the ratio of actual TFP to counterfactual TFP obtained by holding both the level of regulation and the marginal tax rate at their 1949 values. Comparing Figure 12 with Figure 8, which plots the growth rate of TFP over the sample period, shows a close match in the slopes and turning points, suggesting that regulation and the marginal tax rate explain a great deal of the changes in TFP's path, including the productivity slowdown.

The foregoing explanation of the productivity slowdown has an important advantage over alternatives in the literature. Greenwood and Yorukoglu (1997) offer an explanation of the productivity slowdown based on the idea that the economy underwent severe adjustment difficulties in adapting to the large amount of investment expenditure on information technology that began in the late 1970s. Nordhaus (2004) suggests that the productivity slowdown resulted from the OPEC oil shock of the early 1970s. Though both mechanisms may have had a role to play, they cannot be the entire story because the productivity slowdown started five to ten years earlier than either the technology investment or oil shock in the 1970s. In contrast, as we have seen, significant changes in both regulation and marginal tax rates occurred at the start of the productivity slowdown in the mid-1960s and then again at the slowdown's end around 1980.

4.4.C.4: Capital and Labor. We do not dwell on the results for capital and labor because they are of secondary 
interest and are generally of the same character as those for output and TFP. See the last two columns in Table 4 . In particular, regulation has significant effects on both variables, has both growth and cyclical effects, has both linear and non-linear effects on the growth terms, and enters with lags. The pattern of coefficients for labor is very similar to the pattern for output, but the pattern for capital is quite different from those for all the other dependent variables. The different patterns across the three inputs means that changes in regulation causes shifts in the relative amounts of inputs used to produce a given amount of output. Regulation affects not only output's path but also the way output is produced.

4.4.C.5: Consistency with Cross-Section Studies. Our time series results are consistent with most findings of earlier cross-sectional and panel studies. For example, Djankov et al. (2005) and Loayza et al. (2004, 2005) report a negative relation between economic growth and the extent and/or “quality" of regulation. Nicoletti and Scarpetta (2003) find a negative relation between TFP and regulations that restrict competition or entry, and Bassanini and Ernst (2002) find a similar relation for R\&D, which presumably drives TFP. Given that the cross-sectional and panel studies use data constructed in a very different manner and cover a different sample, this agreement suggests the results are robust.

\subsection{Other Models Explored.}

We explored a few other models. First, we tried a difference-stationary ARMA model, extended to allow a time-varying drift rate: ${ }^{22}$

$$
\Delta x_{t}=\beta+\sum_{j=1}^{J_{1}} \gamma_{i} Z_{t-i}+\sum_{j=0}^{J_{2}} \delta_{j} Z_{t-j}^{2}+\sum_{j=1}^{J_{3}} \eta_{j} \Delta x_{t-j}+\sum_{j=1}^{J_{4}} \theta_{j} e_{t-j}
$$

As in the trend-break model, $Z$ is the vector $(R, T)$ and the coefficients $\gamma$ and $\delta$ also are vectors. The patterns and joint significance tests of the coefficient estimates led to similar conclusions as those in the trend-break model. Furthermore, this model is inferior to equation (6) in that it loses an economically important piece of information. Equation (7) is the discrete-time analog to the first-difference of the log of equation (2). Taking the first-difference of the log eliminates the intercept term A(.). That is a major loss of information because A(.) captures the level effects of regulation.

We also explored cointegration among variables and the possibility of estimating an error-correction model.

\footnotetext{
${ }^{22}$ Phillips-Perron tests indicate that all variables have unit roots.
} 
The results were uninformative. Johansen $(1988,1991)$ tests indicate the presence of multiple cointegrating vectors among the variables $Y, N, K, R, G$, and $T$. This result suggests a long-run relationship exists between these variables, but interpretation of individual parameter estimates is unclear in the case of multiple cointegrating vectors. In addition, the number of cointegrating vectors is sensitive to assumptions about lag lengths, trends in the underlying data, the choice of variables included in the analysis, and the inclusion of constant and trend terms in the cointegrating relations themselves, making the choice between alternative models largely arbitrary. These results are not surprising if regulation affects the aggregate economy in the highly nonlinear fashion suggested by our trendbreak model, for cointegration presumes a linear relation.

Furthermore, both the difference-stationary model and cointegration framework require the individual series to be unit-root processes. Although Phillips-Perron tests fail to reject the unit-root hypothesis in the series under examination, it is well known that conventional unit-root tests often fail to reject the unit-root null when the true data generating process is trend-break stationary (Perron, 1989). The underlying aggregate variables being trend-break stationary (as is the current consensus among macroeconomists) would be another reason for the poor performance of the difference-stationary and cointegration models.

Finally, we tried to isolate the CFR titles with significant impacts on our aggregate dependent variables. ${ }^{23}$ However, the large number of titles leaves us too few degrees of freedom to obtain useful results. We could not include any lags. For each possible dependent variable, a small subset of the titles had coefficients individually significant at the 10 percent level or less. However, a joint test of the remaining titles always strongly rejected the null that the remaining titles were jointly insignificant, implying that at least some of the individually insignificant titles are in fact significant. We thus could exclude no individual title and so could not identify which individual titles were significant for any dependent variable.

\footnotetext{
${ }^{23}$ Note that disaggregation by title is not the same as disaggregation by industry affected, nor does it necessarily capture all regulations of a general type. "Agriculture” and "Animals and Animal Products” are separate titles that both affect the agriculture industry. "Banks and Banking" is a title that may affect many industries. For some purposes, it might be preferable to measure some group of related regulations, such as all regulations pertaining to agriculture. This is the approach taken in some of the literature cited in the Introduction.
} 


\section{Conclusion}

We have presented a new time series measuring the extent of federal regulation in the United States, and we have used it to examine the effect of regulation on the macro dynamics of several aggregate variables of interest. We find that post-1949 regulation has statistically and economically significant effects on the time paths of output, total factor productivity, labor, and physical capital. Regulation alters both trends and movements about the trends. The trend effects usually are complex and non-linear. The cycle effects have lag lengths and coefficient sign patterns that differ across the dependent variables. Regulation has allocative effects, changing the mix of factors used to produce output.

Regulation's overall effect on output's growth rate is negative and substantial. Federal regulations added over the past fifty years have reduced real output growth by about one percentage point on average over the period 1949-2005. The main channel through which regulation has reduced output is TFP. We find that federal regulation, together with changes in marginal tax rates, can explain much of the famous and famously puzzling productivity slowdown of the 1970s.

Our results are generally consistent with those obtained from studies using the various cross-country and panel data sets on regulation. The latter are constructed very differently from our data set, covering a subset of total regulations but over an array of countries. That the results agree qualitatively and even quantitatively suggests they are robust. 


\section{References}

Alesina, A., S. Ardagna, G. Nicoletti, and F. Schiantarelli, 2003, “Regulation and Investment,” working paper \#9560, National Bureau of Economic Research, Cambridge, MA.

Averch, H., and L.L. Johnson, 1962, “Behavior of the Firm Under Regulatory Constraint,” American Economic Review 52, 1053-1069.

Barro, R. J., 1981, “Output Effects of Government Purchases,” Journal of Political Economy 89, $1086-1121$.

Bassanini, A., and Ernst, E., 2002, “Labor Market Institutions, Product Market Regulations and Innovation: Cross Country Evidence,” OECD Economics Department Working Papers, No. 316.

Becker G.S., and C.B. Mulligan, 1999, “Accounting for the Growth of Government,” working paper, University of Chicago.

Blanchard, O., 1985, “Debt, Deficits, and Finite Horizons,” Journal of Political Economy 93, $223-247$.

Blanchard, O., and F. Giavazzi, 2003, "Macroeconomic Effects of Regulation and Deregulation in Goods and Labor Markets,” Quarterly Journal of Economics 118, 879-908.

Crain, W.M. and T.D. Hopkins, 2001, “The Impact of Regulatory Costs on Small Firms,” Report SBAHQ-00-R0027, Office of Advocacy, U.S. Small Business Administration (Washington, DC).

Dawson, J.W., 2002, “Measuring Federal Regulation in the U.S.: 1938-1999” working paper, Appalachian State University.

Diebold, F.X., and A. Inoue, 2001, "Long Memory and Regime Switching," Journal of Econometrics 105, 131-159.

Djankov, S., R. LaPorta, F. Lopez-De-Silanes, and A. Shleifer, 2002, “The Regulation of Entry,” Quarterly Journal of Economics 117, 1-37.

Djankov, S., C. McLiesh, and R. Ramalho, 2005, "Regulation and Growth,” World Bank Working Paper, March.

Friedman, M. and R. Friedman, 1979, Free to Choose, New York: Avon Books.

Goff, B, 1996, Regulation and Macroeconomic Performance, Boston: Kluwer Academic Publishers.

Greenwood, J. and M. Yorukoglu, 1997, “1974,” Carnegie-Rochester Conference Series on Public Policy 46, 49-95.

Hamilton, J.D., 1983, “Oil and the Macroeconomy since World War II,” Journal of Political Economy 91, $228-248$.

Hopkins, T.D., 1991, Cost of Regulation (Rochester, NY: Rochester Institute of Technology).

Johansen, S., 1988, “Statistical Analysis of Cointegration Vectors,” Journal of Economic Dynamics and Control 12, 231-254.

Johansen, S., 1991, "Estimation and Hypothesis Testing of Cointegration Vectors in Gaussian Vector Autoregressive Models,” Econometrica 59, 1551-1580.

Kaufman, D., A. Kraay, and M. Mastruzzi, 2003, “Governance Matters,” working paper \#3106, The World Bank, Washington, DC.

Loayza, N.V., A.M. Oviedo, and L. Servén, 2004, “Regulation and Macroeconomic Performance,” World Bank 
Policy Research Working Paper 3469, September.

Loayza, N.V., A.M. Oviedo, and L. Servén, 2005, “The Impact of Regulation on Growth and Informality: CrossCountry Evidence,” AEI-Brookings Joint Center for Regulatory Studies, Related Publication 05-11, May.

Lumsdaine, R.L., and D.H. Papell, 1997, “Multiple Trend Breaks and the Unit-Root Hypothesis,” Review of Economics and Statistics 79, 212-218.

McChesney, F.S., 1987, “Rent Extraction and Rent Creation in the Economic Theory of Regulation,” Journal of Legal Studies 16, 101-118.

Mulligan, C.B., and A. Shleifer, 2003, “Population and Regulation,” working paper, University of Chicago.

Murray, C.J. and C.R. Nelson, 2000, “The Uncertain Trend in U.S. GDP,” Journal of Monetary Economics 46, 7995.

Nelson, C.R. and C.I. Plosser, 1982, "Trends and Random Walks in Macroeconomic Time Series," Journal of Monetary Economics, 10, 139-162.

Nicoletti G., A. Bassanini, E. Ernst, S. Jean, P. Santiago, and P. Swaim, 2001, "Product and Labor Markets Interactions in OECD Countries,” OECD Economics Department Working Papers, No. 312, OECD, Paris.

Nicoletti, G., and F.L. Pryor, 2001, "Subjective and Objective Measures of the Extent of Governmental Regulations,” Swarthmore College Working Paper, December.

Nicoletti, G., and S. Scarpetta, 2003, “Regulation, Productivity and Growth: OECD Evidence,” Economic Policy, April 2003, 9-72.

Nicoletti G. , S. Scarpetta, and O. Boylaud, 2000, "Summary Indicators of Product Market Regulation with an Extension to Employment Protection Legislation,” OECD Economics Department Working Papers, No. 226, OECD, Paris.

Nordhaus, W.D., 2004, “A Retrospective on the 1970s Productivity Slowdown,” NBER Working Paper \#10950.

Parente, S. L., and E. C. Prescott, 1999, Barriers to Riches, Third Walras-Pareto Lecture, University of Lausanne, October.

Peretto, P., 2007a, “Corporate Taxes, Growth, and Welfare in a Schumpeterian Economy,” Journal of Economic Theory 137, 353-382.

Peretto, P., 2007b, “Schumpeterian Growth with Productive Public Spending and Distortionary Taxation,” Review of Development Economics 11, 699-722.

Peretto, P., 2007c, “Energy Taxes and Endogenous Technological Change,” working paper, Duke University.

Peretto, P., 2008, “A Schumpeterian Analysis of Deficit-Financed Dividend Tax Cuts,” working paper, Duke University.

Peretto, P., and M. Connolly, 2007, “The Manhattan Metaphor,” Journal of Economic Growth 12, 329-350.

Perron, P., 1989, “The Great Crash, the Oil Price Shock, and the Unit Root Hypothesis,” Econometrica 57, 13611401.

Pigou, A.C., 1938, The Economics of Welfare, 4th ed. London: Macmillan and Co. 
Stephenson, E.F., 1998, “Average Marginal Tax Rates Revisited,” Journal of Monetary Economics 41, 389-409.

Stigler, G.J., 1971, “The Theory of Economic Regulation,” Bell Journal of Economics and Management Science 2 , 3-21.

Sa, Nelson, 2007, “Sunk Costs, Market Structure, and Welfare: A General Equilibrium Interpretation,” working paper, Duke University.

Ventura, J., 1997, “Growth and Interdependence,” Quarterly Journal of Economics 112, 57-84. 
Table 1

Basic Statistics for CFR Page Count Series

\section{Number of Pages}

Starting Year, 1949

19335

Ending Year, 2005

134261

\section{Growth Rate of Number of Pages}

$\begin{array}{lll}\text { Max } & 0.175 & \text { in } 1950 \\ \text { Min } & -0.052 & \text { in } 1961 \\ \text { Mean } & 0.035 & \\ \text { Median } & 0.027 & \\ \text { Standard Deviation } & 0.039 & \end{array}$

\section{Correlations}

In Number of Pages

$\operatorname{Max}$

0.989

between titles 17 (Commodity and Securities Exchanges) \& 36 (Parks, Forests, and Public Property)

Min

$-0.764$

between titles 26 (Internal Revenue) \& 41 (Public Contracts and Property Management)

Mean

0.603

Median

0.766

Standard Deviation

0.398

In Growth Rate of Number of Pages

Max

between titles 24 (Housing and Urban Development) \& 43 (Public Lands: Interior)

Min

Mean

0.160

Median

0.153

Standard Deviation

0.219 
Table 2

Granger Causality Examples: Growth Rates of Number of Pages

Title 16 - Commercial Practices

Granger-causes:

12 (Banks and Banking), 15 (Commerce and Foreign Trade), 17

(Commodity and Securities Exchanges), 18 (Conservation of Power and

Water Resources), 20 (Employees' Benefits), 21 (Food and Drugs), 33

(Navigation and Navigable Waters), 38 (Pensions, Bonuses, and Veterans'

Relief), 46 (Shipping), 47 (Telecommunication), 49 (Transportation), 50

(Wildlife and Fisheries)

Is Granger-caused by:

7 (Agriculture), 8 (Aliens and Nationality), 15 (Commerce and Foreign Trade), 21 (Food and Drugs), 22 (Foreign Relations), 24 (Housing and Urban Development), 30 (Mineral Resources), 36 (Parks, Forests, and Public Property), 38 (Pensions, Bonuses, and Veterans' Relief), 47 (Telecommunication)

Title 29 - Labor

Granger-causes:

13 (Business Credit and Assistance), 17 (Commodity and Securities Exchanges), 33 (Navigation and Navigable Waters)

Is Granger-caused by:

18 (Conservation of Power and Water Resources), 23 (Highways), 24 (Housing and Urban Development), 42 (Public Health)

Table 3

Bivariate Granger-Causality Tests, 1949-2005

\begin{tabular}{lllll}
\hline \hline Null Hypothesis & $q$ & $N$ & $F$ & $p$-value \\
\hline$\Delta r \nrightarrow \Delta y$ & 4 & 52 & 2.68 & 0.0442 \\
$\Delta y \nrightarrow \Delta r$ & 4 & 52 & 0.43 & 0.7860 \\
\hline$\Delta r \nrightarrow \Delta t f p$ & 4 & 52 & 3.01 & 0.0284 \\
$\Delta t f p \nrightarrow \Delta r$ & 4 & 52 & 0.64 & 0.6339 \\
\hline$\Delta r \nrightarrow \Delta n$ & 4 & 52 & 1.07 & 0.3815 \\
$\Delta n \nrightarrow \Delta r$ & 4 & 52 & 2.04 & 0.1058 \\
\hline$\Delta r \rightarrow \Delta k$ & 4 & 52 & 1.07 & 0.3843 \\
$\Delta k \nrightarrow \Delta r$ & 4 & 52 & 2.17 & 0.0881 \\
\hline
\end{tabular}

Notes: The variables are: $r$ (regulation), $y$ (output), $t f p$ (total factor productivity), $k$ (physical capital), $n$ (labor), where lower case letters denote the natural logs of the variables in question. $\Delta$ is the first difference operator; $q$ is the number of lagged variables in the estimated equation; $N$ is the number of observations. 
Table 4 - Part I

Trend-Break Model Estimation:

Regulation Parameters

\begin{tabular}{|c|c|c|c|c|}
\hline \multicolumn{3}{|c|}{$\begin{array}{c}x_{t}=\alpha+\left[\beta+\sum_{j=)}^{J_{1}} \gamma_{j}^{R} R_{t-j}+\sum_{j=0}^{J_{2}} \delta_{j}^{R} R_{t-j}^{2}+\sum_{j=0}^{J_{1}} \gamma_{j}^{T} T_{t-j}+\sum_{j=0}^{J_{1}} \delta\right. \\
\mathrm{x}=\mathrm{y}\end{array}$} & $\mathrm{x}=\mathrm{n}$ & $\mathrm{x}=\mathrm{k}$ \\
\hline$\gamma_{0}{ }^{\mathrm{R}}$ & $\begin{array}{c}4.25 \mathrm{E}-07 \\
(1.02 \mathrm{E}-07)\end{array}$ & $\begin{array}{c}-4.28 E-08 \\
(3.04 E-09)\end{array}$ & $\begin{array}{c}4.04 \mathrm{E}-07 \\
(1.17 \mathrm{E}-07)\end{array}$ & $\begin{array}{l}-6.06 \mathrm{E}-07 \\
(2.83 \mathrm{E}-07)\end{array}$ \\
\hline$\gamma_{1}^{\mathrm{R}}$ & $\begin{array}{l}-2.95 \mathrm{E}-08 \\
(5.70 \mathrm{E}-08)\end{array}$ & - & $\begin{array}{c}3.79 \mathrm{E}-08 \\
(4.75 \mathrm{E}-08)\end{array}$ & $\begin{array}{c}8.10 \mathrm{E}-07 \\
(2.94 \mathrm{E}-07)\end{array}$ \\
\hline$\gamma_{2}{ }^{\mathrm{R}}$ & $\begin{array}{c}-1.61 \mathrm{E}-07 \\
(4.27 \mathrm{E}-08)\end{array}$ & - & $\begin{array}{l}-3.16 \mathrm{E}-08 \\
(4.18 \mathrm{E}-08)\end{array}$ & - \\
\hline$\delta_{0}{ }^{R}$ & $\begin{array}{c}-1.40 \mathrm{E}-12 \\
(3.49 \mathrm{E}-13)\end{array}$ & - & $\begin{array}{l}-1.81 \mathrm{E}-12 \\
(4.66 \mathrm{E}-13)\end{array}$ & $\begin{array}{c}2.83 \mathrm{E}-12 \\
(1.19 \mathrm{E}-12)\end{array}$ \\
\hline$\delta_{1}^{\mathrm{R}}$ & - & - & - & $\begin{array}{c}-3.82 \mathrm{E}-12 \\
(1.31 \mathrm{E}-12)\end{array}$ \\
\hline$\omega_{0}^{\mathrm{R}}$ & $\begin{array}{l}-0.406 \\
(0.063)\end{array}$ & $\begin{array}{c}0.113 \\
(0.040)\end{array}$ & $\begin{array}{l}-0.373 \\
(0.092)\end{array}$ & $\begin{array}{c}0.404 \\
(0.164)\end{array}$ \\
\hline$\omega_{1}{ }^{\mathrm{R}}$ & - & $\begin{array}{l}-0.143 \\
(0.035)\end{array}$ & - & $\begin{array}{l}-0.359 \\
(0.174)\end{array}$ \\
\hline$\omega_{2}{ }^{R}$ & - & - & - & $\begin{array}{l}-0.221 \\
(0.094)\end{array}$ \\
\hline$\beta_{\mathrm{R}} \Sigma \omega_{\mathrm{j}}^{\mathrm{R}}$ & -0.013 & -0.001 & -0.012 & -0.006 \\
\hline $\begin{array}{l}\Sigma \gamma_{j}^{\mathrm{R}} \\
\left\{\chi^{2} \text { test: } \Sigma \gamma_{j}^{\mathrm{R}}=0\right\} \\
\text { [p-value] }\end{array}$ & $\begin{array}{c}2.35 \mathrm{E}-07 \\
\{12.599\} \\
{[0.000]}\end{array}$ & $\begin{array}{l}-4.28 \mathrm{E}-08 \\
\{\mathrm{NA}\} \\
{[\mathrm{NA}]}\end{array}$ & $\begin{array}{c}4.10 \mathrm{E}-07 \\
\{20.663\} \\
{[0.000]}\end{array}$ & $\begin{array}{c}2.04 \mathrm{E}-07 \\
\{13.705\} \\
{[0.000]}\end{array}$ \\
\hline $\begin{array}{l}\Sigma \delta_{j}^{\mathrm{R}} \\
\left\{\chi^{2} \text { test: } \Sigma \delta_{j}^{\mathrm{R}}=0\right\} \\
\text { [p-value] }\end{array}$ & $\begin{array}{c}-1.40 \mathrm{E}-12 \\
\text { \{NA }\} \\
\text { [NA] }\end{array}$ & - & $\begin{array}{c}-1.81 \mathrm{E}-12 \\
\{\mathrm{NA}\} \\
{[\mathrm{NA}]}\end{array}$ & $\begin{array}{c}-9.86 \mathrm{E}-13 \\
\{9.676\} \\
{[0.002]}\end{array}$ \\
\hline $\begin{array}{l}\Sigma \omega_{j}^{\mathrm{R}} \\
\left\{\chi^{2} \text { test: } \Sigma \omega_{\mathrm{j}}^{\mathrm{T}}=0\right\} \\
{[\mathrm{p} \text {-value }]}\end{array}$ & $\begin{array}{l}-0.406 \\
\{\mathrm{NA}\} \\
{[\mathrm{NA}]}\end{array}$ & $\begin{array}{l}-0.030 \\
\{3.608\} \\
{[0.057]}\end{array}$ & $\begin{array}{l}-0.373 \\
\{\mathrm{NA}\} \\
{[\mathrm{NA}]}\end{array}$ & $\begin{array}{c}0.326 \\
\{21.013\} \\
{[0.000]}\end{array}$ \\
\hline
\end{tabular}

Numbers in parentheses (.) are Newey-West corrected standard errors, brackets [.] are p-values, braces $\{$.$\} are \chi^{2}$ values. Numbers do not always add because of rounding. NA $\equiv$ Not Applicable when there was only one non-zero parameter, making the sum trivial and calculation of $\chi^{2}$ tests superfluous. The value of $\beta_{\mathrm{R}}$ is reported in the text. 
Table 4 - Part II

Trend-Break Model Estimation:

Tax Parameters, Other Parameters, Other Statistics

\begin{tabular}{|c|c|c|c|c|}
\hline & $\mathrm{x}=\mathrm{y}$ & $x=t f p$ & $\mathrm{x}=\mathrm{n}$ & $\mathrm{x}=\mathrm{k}$ \\
\hline$\gamma_{0}{ }^{\mathrm{T}}$ & $\begin{array}{c}0.061 \\
(0.014)\end{array}$ & $\begin{array}{c}-0.209 \\
(0.068)\end{array}$ & $\begin{array}{c}0.050 \\
(0.008)\end{array}$ & - \\
\hline$\gamma_{1}{ }^{\mathrm{T}}$ & $\begin{array}{c}-0.056 \\
(0.013)\end{array}$ & $\begin{array}{c}-0.175 \\
(0.056)\end{array}$ & $\begin{array}{c}-0.033 \\
(0.013)\end{array}$ & - \\
\hline$\gamma_{3}{ }^{\mathrm{T}}$ & - & - & - & - \\
\hline$\delta_{0}{ }^{\mathrm{T}}$ & - & $\begin{array}{c}0.512 \\
(0.190)\end{array}$ & - & - \\
\hline$\delta_{1}{ }^{\mathrm{T}}$ & - & $\begin{array}{c}0.432 \\
(0.156)\end{array}$ & - & - \\
\hline$\omega_{0}{ }^{\mathrm{T}}$ & - & $\begin{array}{c}0.181 \\
(0.037)\end{array}$ & - & $\begin{array}{c}0.097 \\
(0.059)\end{array}$ \\
\hline$\omega_{1}{ }^{\mathrm{T}}$ & - & - & - & $\begin{array}{c}0.065 \\
(0.053)\end{array}$ \\
\hline$\omega_{2}{ }^{\mathrm{T}}$ & - & - & - & $\begin{array}{c}0.165 \\
(0.064)\end{array}$ \\
\hline$\beta_{\mathrm{T}} \Sigma \omega_{\mathrm{j}}^{\mathrm{T}}$ & - & 0.001 & - & - \\
\hline $\begin{array}{l}\Sigma \gamma_{j}^{\mathrm{T}} \\
\left\{\chi^{2} \text { test: } \Sigma \gamma_{j}=0\right\} \\
\text { [p-value] }\end{array}$ & $\begin{array}{l}-0.0054 \\
\{0.233\} \\
{[0.629]}\end{array}$ & $\begin{array}{c}-0.384 \\
\{16.488\} \\
{[0.000]}\end{array}$ & $\begin{array}{c}0.017 \\
\{3.885\} \\
{[0.049]}\end{array}$ & - \\
\hline $\begin{array}{l}\Sigma \delta_{j}^{\mathrm{T}} \\
\left\{\chi^{2} \text { test: } \Sigma \delta_{j}^{\mathrm{R}}=0\right\} \\
\text { [p-value] }\end{array}$ & - & $\begin{array}{c}0.0943 \\
\{29.006\} \\
{[0.000]}\end{array}$ & - & - \\
\hline $\begin{array}{l}\Sigma \omega_{j}^{\mathrm{T}} \\
\left\{\chi^{2} \text { test: } \Sigma \omega_{j}^{\mathrm{T}}=0\right\} \\
\text { [p-value] }\end{array}$ & - & $\begin{array}{l}0.181 \\
\{\mathrm{NA}\} \\
{[\mathrm{NA}]}\end{array}$ & - & $\begin{array}{c}0.326 \\
\{21.013\} \\
{[0.000]}\end{array}$ \\
\hline$\alpha$ & $\begin{array}{c}11.2000 \\
(0.639)\end{array}$ & $\begin{array}{c}1.085 \\
(0.182)\end{array}$ & $\begin{array}{c}8.324 \\
(0.952)\end{array}$ & $\begin{array}{l}10.222 \\
(0.497)\end{array}$ \\
\hline$\beta$ & $\begin{array}{c}0.038 \\
(0.002)\end{array}$ & $\begin{array}{c}0.051 \\
(0.006)\end{array}$ & $\begin{array}{c}-0.002 \\
(0.002)\end{array}$ & $\begin{array}{c}0.032 \\
(0.002)\end{array}$ \\
\hline Adj. $R^{2}$ & 0.998 & 0.995 & 0.994 & 0.999 \\
\hline
\end{tabular}

Numbers in parentheses (.) are Newey-West corrected standard errors, brackets [.] are p-values, braces \{.\} are $\chi^{2}$ values. Numbers do not always add because of rounding. NA $\equiv$ Not Applicable when there was only one non-zero parameter, making the sum trivial and calculation of $\chi^{2}$ tests superfluous. The value of $\beta_{\mathrm{T}}$ is reported in the text. 


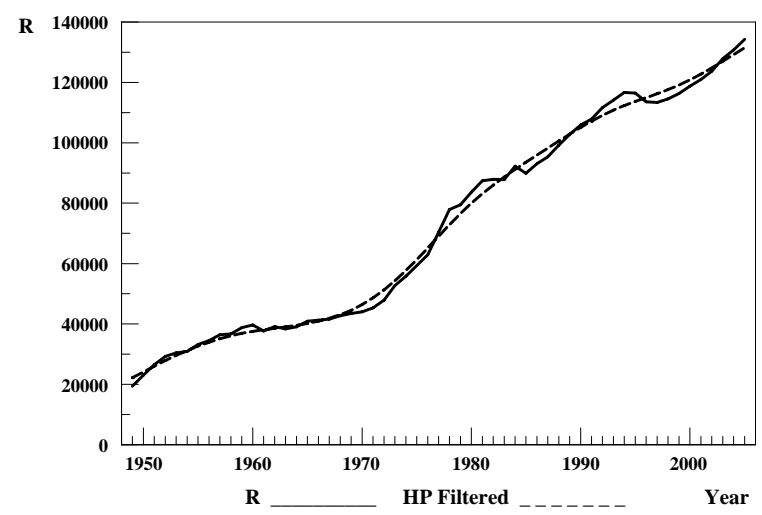

Fig. 1: Regulation over time

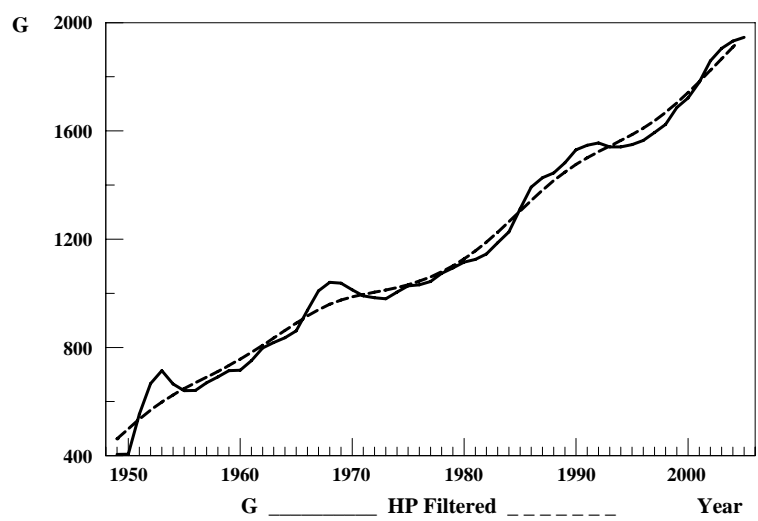

Fig. 3: Government purchases over time

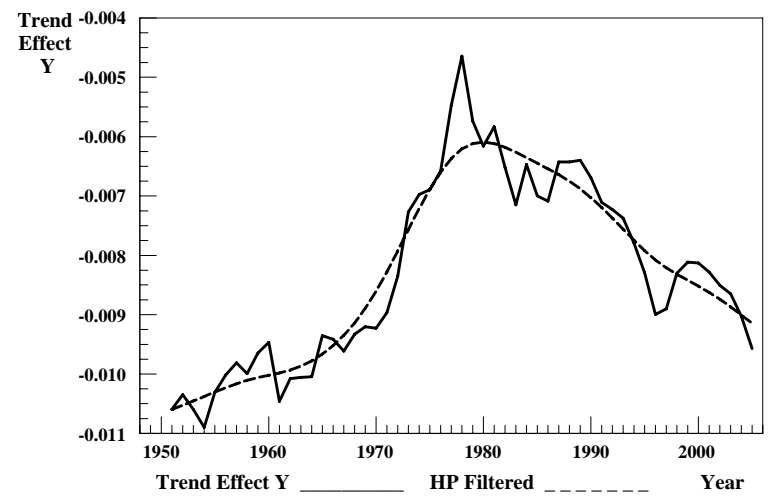

Fig. 5: Effect of R on Y trend

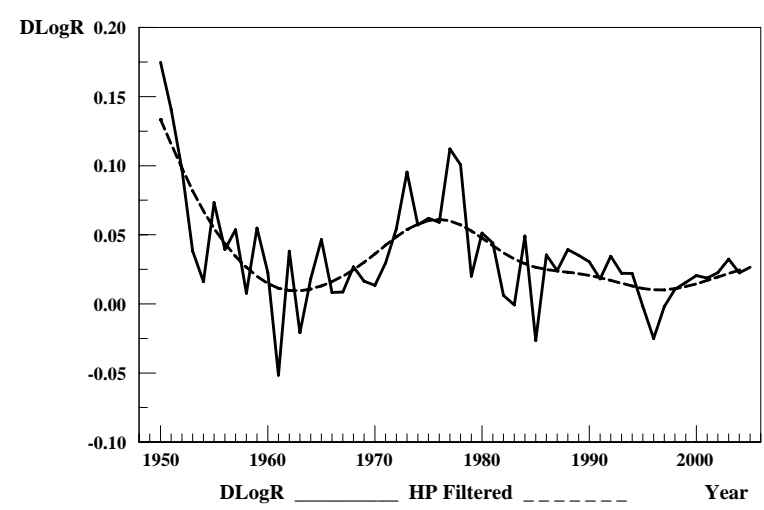

Fig. 2: Growth rate of regulation over time

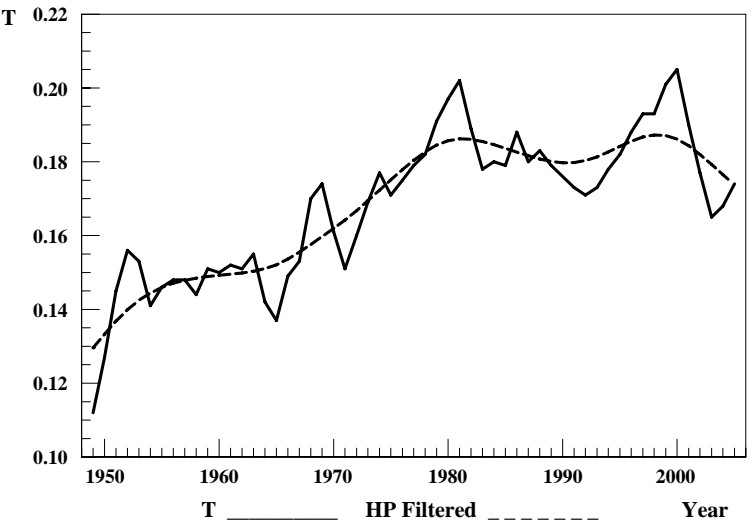

Fig. 4: Marginal tax rate over time

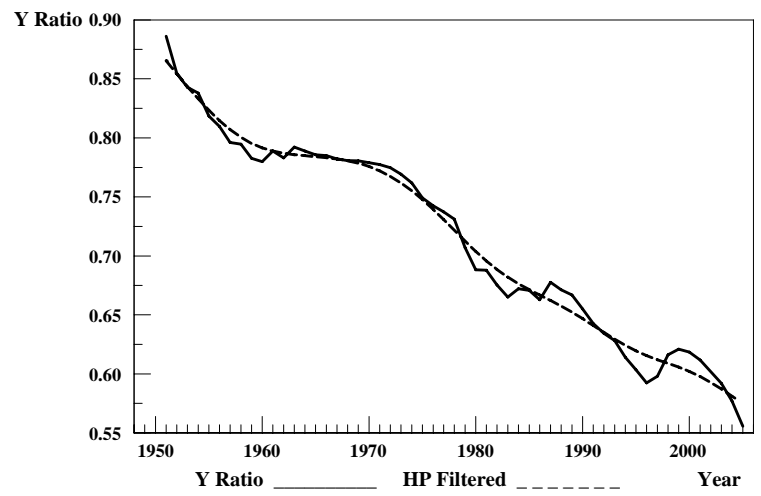

Fig. 6: Ratio of actual Y to counterfactual $\left.\mathrm{Y}\right|_{\mathrm{R}=\mathrm{R}(1949)}$ 


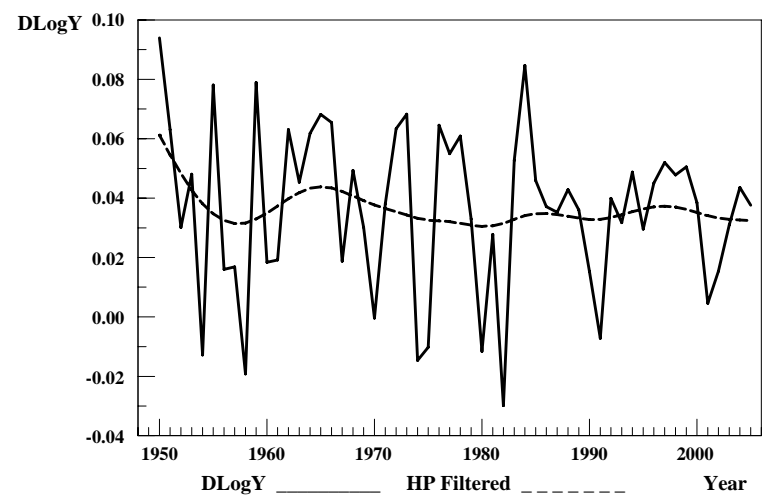

Fig. 7: DLogY

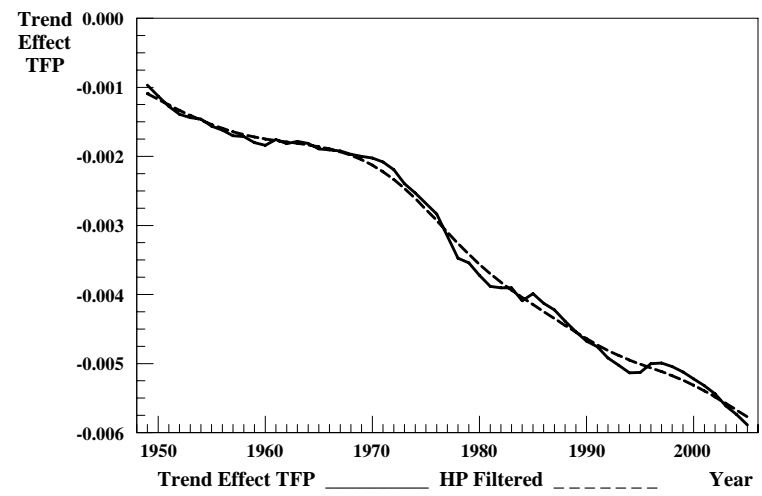

Fig. 9: Effect of R on TFP trend

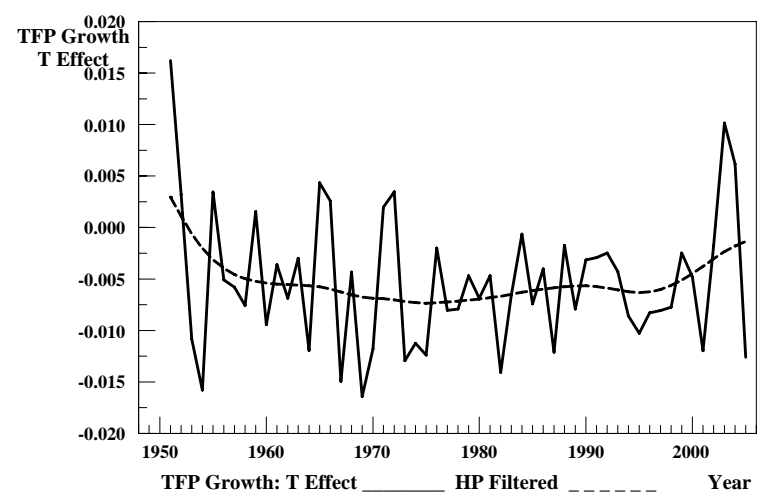

Fig. 11: Change in Ratio of actual TFP to counterfactual TFP $\left.\right|_{\mathrm{T}=\mathrm{T}(1949)}$

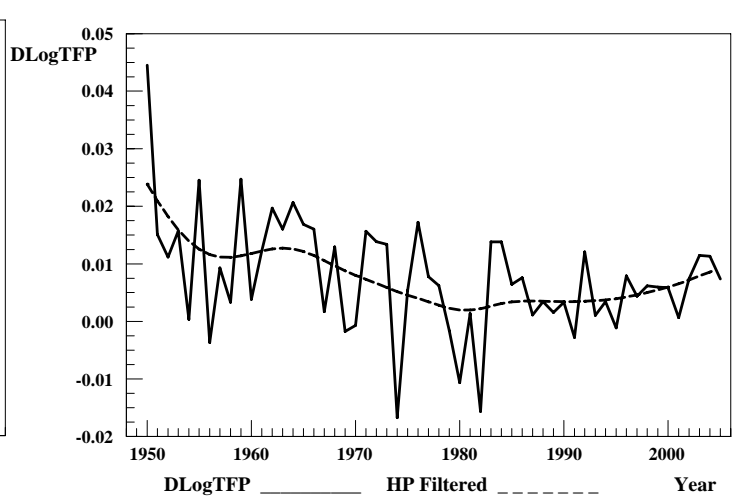

Fig. 8: DlogTFP

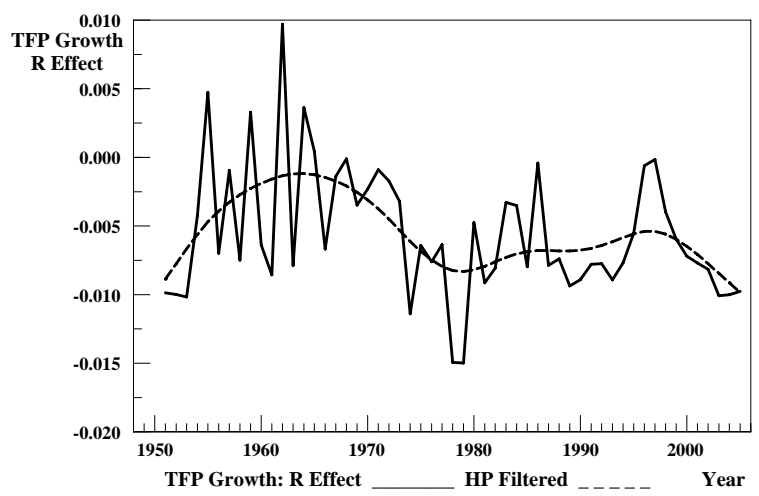

Fig. 10: Change in Ratio of actual TFP to counterfactual TFP $\left.\right|_{\mathrm{R}=\mathrm{R}(1949)}$

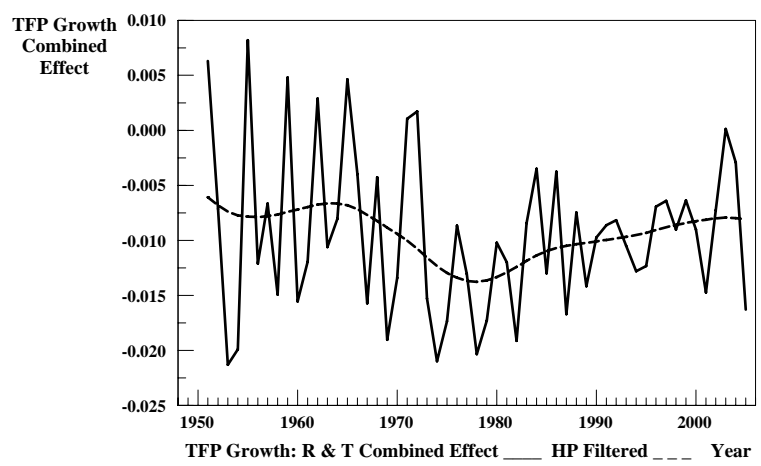

Fig. 12: Change in Ratio of actual TFP to counterfactual TFP $\left.\right|_{\mathrm{R}=\mathrm{R}(1949), \mathrm{T}=\mathrm{T}(1949)}$ 


\title{
Appendix: Code of Federal Regulations
}

\section{History and Background of the Code of Federal Regulations}

Before 1935, no systematic process existed for the promulgation of federal regulations; regulations were simply typed and filed by individual agencies. The lack of public notification regarding regulatory activity later came to be known as "hip pocket" law, which led the government to embarrassment in Panama Refining Company $v$. Ryan (293 U.S. 388, 1935), also known as the "Hot Oil Case." ${ }^{24}$ The government's case, which was based on a provision that was later nullified by a subsequent regulation, was dismissed by the Supreme Court, and both parties in the case were impugned for their ignorance of the law. This outcome led to the Federal Register Act of 1935 (49 Stat. 500; 44 USC Chapter 15), which established a consistent framework for codification of government regulations throughout the rulemaking process.

The Federal Register (FR), first published on March 14, 1936, is a daily publication in which proposed regulations appear first in draft form and eventually in final form, if passed into law. The FR also contains presidential proclamations, executive orders, announcements of agency hearings and meetings on regulatory issues, grant application instructions and deadlines, official agency decisions and actions, and agency establishments, reorganizations, and dissolutions. Sometimes, there also are long sections containing technical or economic analyses or discussion of issues arising during consideration of a proposed regulation. The final regulations (newly passed into law) contained in the FR ultimately are codified in the Code of Federal Regulations (CFR). Divided into 50 subject categories called titles, the structure of the CFR is similar, but not identical, to that of the United States Code. Currently, each title of the CFR is revised annually and contains all regulations in effect as of the cover date. ${ }^{25}$

The first edition of the CFR published regulations in force as of June 1, 1938. In the early years, the CFR was not revised annually. Instead, annual supplements carried in full text all changes and additions to the 1938 edition of the CFR as published in the FR. The supplements covered the periods June 2-December 31, 1938 and subsequent calendar years through 1941, listing regulatory changes promulgated during the period and in effect on December 31 of the year in question. ${ }^{26}$ The first revision of the CFR, scheduled for June 1, 1943 under the Federal Register Act, was postponed because of the volume of rapidly changing regulations related to World War II and the preoccupation of all government agencies with the war effort. In its place, a cumulative supplement to the 1938 edition of the CFR compiled regulations in force as of June 1, 1943. However, regulations in effect at that date whose text was identical to that in the 1938 edition of the CFR are included only by reference to the original CFR. Also, emergency controls associated with the war period are recorded by tabulation rather than codification in the cumulative supplement. Thus, the cumulative supplement served as an adjunct to the original edition rather than a replacement of it. Following the cumulative supplement, annual supplements continued to update the 1938 edition of the CFR for regulatory changes published in the FR during the remainder of 1943 and each calendar year through 1947. The wartime suspension of the first revision of the CFR was terminated in 1948 and the second edition of the CFR, recording regulations in effect on January 1,1949 , was issued. ${ }^{27}$

Following the 1949 edition of the CFR, "pocket supplements" were used to record regulatory changes

\begin{abstract}
${ }^{24}$ Throughout the appendix, the following citation format is used: volume or title number followed by name of publication followed by page or section number. For example, "49 Stat. 500" designates Volume 49 of the United States Statutes at Large, page 500. The following abbreviations are also used in the citations: USC for United States Code, FR for Federal Register, and CFR for Code of Federal Regulations.
\end{abstract}

${ }^{25}$ The U.S. Statutes at Large and U.S. Code are comparable to the Federal Register and Code of Federal Regulations, respectively, except that the former are primarily concerned with the publication and codification of laws, whereas the later are concerned with transmitting to the public written requirements to be carried out and enforced by government agencies (i.e., regulations). Thus, the CFR is more appropriate than the U.S. Code as a measure of regulation.

${ }^{26}$ No supplement was published for 1942 .

${ }^{27}$ Due to the imminence of the second edition of the CFR, no supplement was issued for 1948. Regulatory changes published in the FR during 1948 were codified for the first time in the 1949 edition of the Code. 
published in the FR. ${ }^{28}$ Pocket supplements differed from the annual supplements to the first edition of the CFR in that they were cumulative; that is, the pocket supplement for a given year recorded the full text of all changes to the 1949 CFR in effect at the end of the given year, irrespective of the year that the change occurred. The first pocket supplement covered changes during the June 2 to December 31, 1949 period and subsequent pocket supplements included any additional changes in effect at the end of each succeeding calendar year. So, for example, the 1950 pocket supplement documents changes to the 1949 edition of the CFR that occurred between June 2, 1949 and December 31, 1950. Some of those changes occurred between June 2 and December 31 of 1949 and so already were reported in the 1949 pocket supplement. The 1950 pocket supplement repeats them and adds all changes that occurred between January 1 and December 31 of $1950 .^{29}$

From time to time, as warranted by growth of the pocket supplements, individual titles (or individual parts of a title) of the 1949 CFR were revised. These revisions represented a complete codification of regulations in effect as of December 31 of the year in which they were published. The timing of revisions varied considerably across titles. In all titles, however, revisions became more frequent over time. In 1950, for instance, only Parts 71-90 of Title 49 (Transportation and Railroads) were revised. In 1960, all or parts of Titles 1-5, 14, 18-20, 26, 27, 32, 40, 41, 49, and 50 were revised, and by 1968, all except Titles 34, 35, and 37 were revised. Beginning in 1969, all titles of the CFR have been revised annually. ${ }^{30}$

\section{Measuring Regulatory Activity Using the CFR}

The consistent codification of federal regulations in the CFR since its inception in 1938 provides a unique source of information on regulatory activity over the years. Dawson (2002) constructs series measuring regulatory activity based on the number of pages published in the CFR's various editions and supplements. Although the number of pages of regulation cannot capture the differential effects of alternative regulations on economic activity, it affords new information on the temporal behavior of the total amount of regulation in place. The remainder of this section provides a summary of these CFR-based measures of regulation. For a complete description of the methodology used to construct the series and a statistical comparison of the various series, see Dawson (2002).

Before counting pages, we must standardize the pages in the CFR for different words per page across the years. That turns out to be almost effortless. The CFR uses the same font and page size in all years except the very first, 1938. We converted 1938 pages to "standard" pages simply by multiplying by an adjustment factor based on average words per page computed by sampling words per page in each title of the Code. Even this adjustment turns out to be irrelevant to our empirical work below because, for reasons to be explained momentarily, we started our sample period in 1949, thus omitting the non-standard 1938 edition of the Code entirely.

Measuring regulatory activity using data on the number of pages in the CFR is straightforward in years when the CFR is revised. These include the years 1938, 1949, all years after 1969, and some years between 1949 and 1969. ${ }^{31}$ Estimating total pages of regulation during the periods between the 1938, 1949, and subsequent revisions is more problematic. One approach, which explicitly uses all annual and pocket supplement data to estimate total pages of regulation during years in which no revision is published, adds the number of pages in a nonrevision-year's supplement to the number of pages in its corresponding complete CFR. The series that results

\footnotetext{
${ }^{28}$ The term "pocket supplement" derives from pockets which were made in the books of the 1949 edition of the CFR for placement of the forthcoming supplements.

${ }^{29}$ On several occasions, an "added pocket part" (APP) was published instead of a pocket supplement. The APP served as an addition or supplement to the previous year's pocket supplement. APPs were not cumulative unless they appeared in consecutive years, in which case the old APP was replaced by the current APP as a supplement to the most recent pocket supplement.

${ }^{30}$ Beginning with the 1973 revision of the CFR, the effective revision date of each title varies within the year according to the following quarterly schedule: Titles 1-16 as of January 1; Titles 17-27 as of April 1; Titles 2841 as of July 1; and Titles 42-50 as of October 1.

${ }^{31}$ Recall from the discussion above that the timing of revisions to the 1949 edition of the CFR varies across titles between the years 1949 and 1969.
} 
from this methodology exhibits rapid growth in pages of regulation during most of the 1940s followed by a drastic decline in 1949. This behavior in part may reflect the increase in regulation associated with World War II and the subsequent decrease following the war, but it also is likely to reflect in part an element of double counting that is, for practical purposes, unavoidable with the supplements used to codify regulatory changes between the 1938 and 1949 revisions of the CFR. The supplements print the entire text of any section of regulation that changed, even if only one word was different. Consequently, a page of text in a supplement may represent completely new text that was not present in 1938 or may be almost entirely repetition of previously existing text. The only way to avoid double counting repeated text would be to read each reported change to determine how much of it was repetition, an obviously impractical task. Growth in the estimated pages of regulation resumes in the early 1950s and moderates into the 1960s. The same double counting problem exists after 1949 as before but is less severe because revised volumes of the CFR were published intermittently between 1949 and 1969. The frequency of these intermittent updates increased as time passed, with almost the entire CFR being revised in 1968. Consequently, the growth in the CFR page count between 1949 and 1969 is much more likely to be a genuine phenomenon than is the pre-1949 growth. Double-counting ceases to be an issue after 1968 because the entire CFR is published every year after that. Because the counting problems are much more severe before 1949 than after, we restrict attention in our study to the period 1949-1999..$^{32}$ Also, because we are interested in the effects of regulation on the private economy, we exclude from our page count all regulations in the first six titles, which pertain to the internal organization and operation of the federal government itself.

\section{Comparison with Other Measures of Regulation}

3.1. Description. Our measure covers one country over 54 years; earlier measures cover many countries over much shorter periods of time. ${ }^{33}$ Some of the earlier measures are purely cross-sectional, applying to a single year; others cover more years and so are panel data. The longest time span of the panel sets is 20 years.

Our measure is more comprehensive than any of its predecessors. Federal law requires that all federal regulations be published in the CFR, so our measure includes literally every regulation issued by the federal government. No other measure of regulation comes close to that extent of coverage. For example, the most widely used of the earlier data sets is the OECD cross-section measure described by Nicoletti et al. (2000) and extended in part to a 20-year panel by Nicoletti et al. (2001). The cross-section data are restricted to product market and employment protection regulation; other types, such as environmental or occupational health and safety regulation, are ignored. The panel extension is restricted further to a small subset of seven non-manufacturing industries: gas, electricity, post, telecommunications, passenger air transport, railways and road freight. Types of regulations considered also are limited, with data availability varying by industry: barriers to entry (available for all industries), public ownership (all industries except road freight), vertical integration (gas, electricity and railways), market structure (gas, telecommunications and railways), and price controls (only road freight).

All measures of regulation including ours are aggregate indices. Our index is more highly aggregated than any of the others simply because it covers the full array of regulations, but all are aggregates. None simply reports a quantitative measure of the magnitude or effect of a single regulation. The OECD measure, for example, collects answers to about 1300 questions and combines them into an index through a multistep aggregation procedure. The methods of aggregation differ substantially across indices. Our method is to weight each regulation by its number of pages in the CFR, which captures at least partially the complexity of the regulation, as we discuss below. Many other indices are constructed as simple averages of basic data, with no attempt to weight by the importance or complexity of the regulations included. The OECD uses a multistep procedure, in which the OECD staff creates a

${ }^{32}$ Dawson (2002) discusses the "double-counting” problem in more detail and offers some alternative methods for constructing the regulatory series based on interpolation in the non-revision years. The results of the analysis in this paper are not sensitive to the construction method, thus we restrict attention to the series discussed here.

${ }^{33}$ See Nicoletti et al. (2000), Nicoletti et al. (2001), Djankov et al. (2002), Kaufman, Kraay, and Mastruzzi (2003), Nicoletti and Scarpetta (2003), Loayza et al. (2004), and Djankov et al. (2005) for detailed descriptions of these alternative measures. 
collection of categorical sub-aggregates mostly as simple averages of basic data and then uses factor analysis to aggregate those into its final indices.

All measures except ours are based at least in part on survey data, typically obtained from questionnaires sent to government officials (OECD), market participants (Kaufman et al.), and/or lawyers (Djankov, 2002). Our measure is based solely on the page count of the CFR.

3.2. Evaluation. Our measure is a pure time series covering a long time span. The earlier measures of regulation have short to non-existent time spans, the longest being 20 years and the shortest 1 year. Such data cannot be used to study regulation's effects on macroeconomic dynamic adjustment paths, which requires following the evolution of variables through time. There is more hope of studying regulation's effects on average growth rates by using the cross-sectional dimension of the data to overcome the inadequate time dimension, which is precisely what several of the previous studies do. However, growth is an intertemporal phenomenon, so it would be useful to have time series estimates of regulation's effects on it, especially in light of Ventura's (1997) demonstration that the interpretation of cross-country growth regressions is confounded by the effects of foreign trade. Our measure, with its comparatively long time dimension, allows us to study both the long-run growth and short-run dynamic adjustment effects of regulation. The earlier studies, with their strong cross-section element but weak intertemporal element, are better suited for cross-sectional issues.

Our measure also is more comprehensive than the earlier measures, none of which encompasses the total set of regulations in any country. Incomplete coverage leads to two problems: (1) omitted variables bias, and, in any time series study, (2) divergence between the time series behavior of subsets of regulation on the one hand and of total regulation on the other.

Table 1 shows that the page counts of the various titles of the CFR are highly correlated with one another, whether measured in levels or growth rates. The mean correlation among levels is 0.60 , with an even higher median of 0.77 . The maximum correlation in levels is 0.99 , and the minimum correlation is -0.76 . The correlations in growth rates are much lower, of course, with a mean of only 0.16 (median of 0.15 ), but there still are quite a few correlations of substantial magnitude, with the maximum and minimum being 0.74 and -0.63 , respectively. ${ }^{34}$ Such high correlations show that including just one type of regulation in a statistical analysis is likely to be misleading because of multicollinearity and consequent omitted variables problems. The problem is even more severe when addressing issues of macroeconomic dynamics. The correlations in Table 1 are all contemporaneous; for analyzing time series behavior, we also want to know the dynamic relations among various types of regulations. Grangercausality tests show the intertemporal dependence of one series on another after accounting for the first series's dependence on its own lagged values. Table 2 summarizes Granger-causality test results for two titles of the CFR related to the kinds of regulations studied in previous analyses-regulation of entry and regulation of labor markets. Title 16 of the CFR pertains to Commercial Practices, and Title 29 pertains to Labor. Table 2 shows that the page counts of those titles both Granger-cause and are Granger-caused by the page counts of other titles, some apparently quite unrelated in content to the subjects of titles 16 and 29. Similar results hold for most of the other titles of the CFR. These Granger-causality relations among CFR titles show that there are temporal orderings in the statistical relations among the types of regulation and provide strong evidence that a time series analysis restricted to a subset of regulations is likely to suffer from serious omitted variables bias.

The foregoing remarks have greatest force when applied to attempts to study the economic effects of a particular type of regulation. If one is interested in the impact of total regulation, the high correlations among the different types might actually be considered good news because they suggest that a subset of regulations may capture the behavior of the whole. Indeed, Nicoletti et al. (2001), who have perhaps the most restricted measure of all, interpret their indicators as "a proxy for the overall regulatory policies followed by OECD countries over the sample period (p. 43).”

Unfortunately, examination of the data shows this hope to be ill-founded. Nicoletti et al.'s (2001) measure spans 1978-98 and shows a 66\% decline over that period. Subsets of CFR titles corresponding to Nicoletti et al.'s measure behave similarly. For example, titles 23 (Highways), 46 (Shipping), and 49 (Transportation) of the CFR encompass regulation of air transport, railways, and road freight, one Nicoletti et al.'s regulation groups. The page count of titles 23, 46, and 49 drops from a total of 8400 in 1978 to 8261 in 1998, which is qualitatively the same behavior as Nicoletti et al.'s measure. Nevertheless, the page count of the total CFR displays the opposite behavior,

\footnotetext{
${ }^{34}$ Similarly, Loyaza et al. (2005) found very high correlations among their 7 indices of regulation.
} 
rising $47 \%$ over $1978-98$. The inescapable implication is that subsets of regulation are not reliable proxies for total regulation.

Our measure of regulation is the only measure constructed by a completely objective method. Our measure consists of the page counts in the CFR, a number requiring no judgement to obtain. Subjectivity enters all other measures in two ways. First, as remarked above, all other measures are based at least in part on survey data. As Nicoletti et al. (2000) note, the people completing the surveys have some latitude in interpreting the survey questions and may respond idiosyncratically. Second, the survey must be designed and the responses must be combined, processes that involve the judgement of the investigator. For example, the OECD index begins with responses to about 1300 survey questions. The responses usually are Yes or No. Groups of these responses are combined by averaging to create categorical variables with values from 0 to 6 . The procedure used for measuring the scope of public enterprise illustrates the issues. Respondents are asked if there are "national, state or provincial government controls in at least one of" 24 industries chosen by the OECD. Some of the industries chosen are 2-digit ISIC (e.g., wholesale trade, financial institutions), some are 3-digit (e.g., tobacco manufactures), and some are 4-digit (e.g., electricity, motion picture distribution and projection). Despite the differences in size and importance, all industries have been assigned the same weight of 1 in the construction of the categorical variables. See Table A2.1.1 in Nicoletti et al. (2000), p.60, for details. ${ }^{35}$ Other measures of regulation are generally more subjective than the OECD's. An oddity that results from subjectively deciding what is and is not regulation is that two of the published measures of regulation contain elements that have nothing to do with regulation. The OECD measure includes data on publicly-owned enterprises, a form of government intervention but not regulation. Loayza et al.'s (2005) measure includes data on spending and taxation and on the fraction of the workforce that is unionized, neither of which pertains to regulation. These measures thus confound regulation with other government and even non-government activities.

Some indices of regulation attempt to measure the burden imposed by the component regulations by including quantitative and/or qualitative data pertaining to the regulations included. Examples include the number of procedures a new firm must go through to start operation (Djankov et al., 2002) and regulatory complexity (OECD; Nicoletti et al., 2000). Our measure contains no such direct measures but nonetheless controls for regulatory burden to some extent. It seems reasonable to suppose that, on average at least, the more complex a regulation, the more pages it will require. Indeed, the OECD measures complexity by the presence or absence of a long list of regulatory requirements. The larger the number of requirements, the more the pages of regulations necessary to describe them, which is precisely what our measure captures. Indeed, our approach may give a more complete picture of regulatory burden than the OECD's measure because page counts indicate not only the presence or absence of particular provisions but also their complexity.

3.3. Summary. Our page count measure of the extent of regulation compares well with other measures. Although limited to a single country, it has a much longer time span than any other measure. It is unique in being totally comprehensive. ${ }^{36}$ It also is unique in being $100 \%$ objective both in the data underlying it and in the method of constructing the index. It offers indicators at two levels of aggregation-one final index for total regulation and many sub-indices for the different classes (“titles”) of regulation. It is easily replicated and easily updated. Finally, CFR page counts are a more precise measure of regulation than page counts of other federal publications, such as the Federal Register or the U. S. Code, suggested by others. ${ }^{37}$ The Federal Register contains proposed regulations and other irrelevant material; the $U$. S. Code contains all federal laws, not just regulations.

${ }^{35}$ Nicoletti and Pryor (2001) argue that the OECD measure is objective, but it clearly is not. Indeed, in describing its construction, Nicoletti et al. (2000) say that $90 \%$ of the data underlying the OECD measure is "survey data" (p.11) and that both questionnaire responses and the procedure for scoring them involved "subjective judgement” (p.16).

${ }^{36}$ At least for federal regulations. Our measure does not include state and local regulations.

${ }^{37}$ Friedman and Friedman (1979) use the number of pages in the Federal Register to measure the growth of regulation. Becker and Mulligan (1999) use pages in the U.S. Code as a measure of growth in the size of government. Mulligan and Shleifer (2003) use kilobytes of unannotated state law, where $1 \mathrm{~kb}$ approximately equals one printed page, to study the causes of regulation. 